\title{
A Novel Hybrid MCDM Model for the Evaluation of Sustainable Last Mile Solutions
}

\author{
Mladen Krstićc (D, ${ }^{1}$ Snežana Tadić, ${ }^{1}$ Milovan Kovač, ${ }^{1}$ Violeta Roso, ${ }^{2}$ and Slobodan Zečevićc \\ ${ }^{1}$ Logistics Department, Faculty of Transport and Traffic Engineering, University of Belgrade, Vojvode Stepe 305, Belgrade 11000, \\ Serbia \\ ${ }^{2}$ Division of Service Management and Logistics, Chalmers University of Technology, Chalmersplatsen 4, 412 96 Göteborg, Sweden \\ Correspondence should be addressed to Mladen Krstić; m.krstic@sf.bg.ac.rs
}

Received 1 July 2021; Revised 16 September 2021; Accepted 17 September 2021; Published 6 October 2021

Academic Editor: Jean Jacques Loiseau

Copyright (c) 2021 Mladen Krstić et al. This is an open access article distributed under the Creative Commons Attribution License, which permits unrestricted use, distribution, and reproduction in any medium, provided the original work is properly cited.

\begin{abstract}
Modern social trends are intensively transforming supply chains and the last mile as their most complex and most expensive segment. For the realization of the last mile, various solutions can be defined which combine initiatives, technologies, and concepts of city logistics. The successful implementation of these solutions depends on the characteristics of the city, the goals of stakeholders, and the ability to achieve economic, social, and environmental sustainability. In accordance with that, this paper defines innovative sustainable last mile solutions and evaluates their potential application in the real-life logistics system of the city. As evaluation requires consideration of a large number of criteria, this is a problem of multicriteria decision-making, and for solving it, a novel hybrid model that combines Delphi, FARE (Factor Relationship), and VIKOR (Višekriterijumska Optimizacija i Kompromisno Rešenje) methods in the fuzzy environment has been developed. The applicability of the model is demonstrated in the example of evaluating the last mile solution for the central business district of the City of Belgrade. A combination of microconsolidation centers and autonomous vehicles is obtained as the most favorable solution.
\end{abstract}

\section{Introduction}

Globalization, growth of consumer society, the shift of production paradigm based on individualization, personalization and shorter product life, development of the industry 4.0 based on technological progress, automation, digitalization, networking and new forms of communication, development of e-commerce, sustainability, and other modern trends intensively transform the ways of realization of goods and transport flows. Requirements for efficient realization of supply chains are becoming increasingly strict, which is especially expressed in the realization of the last mile as their most complex and most expensive segment. The last mile is realized in the urban environments that are characterized by various economic, geographical, sociological, cultural, historical, and demographic features, architectural heritage, habits, and perceptions of the population, etc. [1]. In addition, there are various stakeholders in the cities (users, logistics providers, residents, and city administration) whose goals define the requirements for planning and implementation of the last mile in accordance with the principles of economic, social, and environmental sustainability. Accordingly, the subject of this paper is the creation of sustainable last mile solutions (LMSs) by combining different initiatives, technologies, and concepts of city logistics (CL). The goal is to evaluate and rank them and analyze the possibility of their application in the real-life logistics system of the city.

As it requires consideration of a large number of criteria, the problem of multicriteria decision-making (MCDM) is defined in the paper. The existing literature demonstrated many examples of combining different MCDM methods, but there are no examples of combining the FARE (Factor Relationship) with Delphi and VIKOR (Višekriterijumska Optimizacija i Kompromisno Rešenje) methods. Furthermore, the scientific literature lacks articles that define innovative, sustainable LMSs and evaluate them from a multicriterial perspective. This article fulfills these research 
gaps by defining innovative and potentially sustainable LMSs and evaluating them through a wide set of defined criteria with a novel hybrid model that combines Delphi, FARE, and VIKOR methods in the fuzzy environment. The applicability of the model is demonstrated in the example of ranking sustainable LMSs in the City of Belgrade. A combination of microconsolidation centers and autonomous vehicles was obtained as the most favorable solution in relation to the observed criteria.

The paper is organized as follows: Section 2 provides an overview of the literature on the methods that make up the MCDM model and the initiatives, technologies, and concepts that form the sustainable LMSs. After that, in Section 3, the structure of the defined model is given and the steps of its application are described. Section 4 describes the LMSs applicable in the City of Belgrade, as well as the criteria for their evaluation. The application of the model for solving the defined problem and the sensitivity analysis are also presented in the same section. Sections 5 and 6 discuss the achieved results and the conclusions and directions for future research, respectively.

\section{Literature Review}

This section provides an overview of the literature on recent applications of MCDM methods, the methods that make up the proposed hybrid MCDM model, concepts, technologies, and initiatives that could be combined to form sustainable solutions for the realization of the last mile, as well as the criteria for their evaluation.

\subsection{Overview of Recent MCDM Method Applications.} Using MCDM methods for solving multicriterial problems is a popular topic in the existing literature [2]. Besides the conventional form, the developed MCDM models in the literature were also applied in various uncertainty environments-fuzzy, grey, rough, neutrosophic, etc. [3]. Novel MCDM methods [4] and hybrid models [5] are regularly proposed in the literature for solving decision-making problems in various fields.

The long-established and widely accepted MCDM methods, such as AHP, TOPSIS, and VIKOR, find extensive application to this day. In recent years, the AHP method was used for selecting routes for oversized cargo transport [6], identifying the most relevant sustainability issues [7], selecting sustainable projects [8], etc. The TOPSIS method found its application for reverse logistics performance evaluation [9], policy selection for developing electric vehicle systems [10], supplier selection [11], etc. The VIKOR method was recently used for risk evaluation [12], selection of supplier portfolio of key outsourcing parts [13], selection of industrial robots [14], etc. The existing literature is also abundant in newly introduced methods such as CODAS [15], KEMIRA [16], PIPRECIA [17], and MARCOS [18]. Aside from applying MCDM methods independently, many literature articles propose and develop hybrid MCDM models by combining two or more MCDM methods. Various MCDM models can be found in the literature, such as DEMATEL-AEF-VIKOR [19], SERVQUAL-AHP-TOPSIS [20], DANP-FUCOM-VATOPSIS [21], SSC-VIKOR [22], SWARA-MARCOS [23], and KEMIRA-BWMMOORA [24].

\subsection{Overview of the Methods That Make Up the MCDM Model.} The paper proposes a novel hybrid MCDM model that combines the fuzzy Delphi, fuzzy FARE, and fuzzy VIKOR methods. The fuzzy FARE method was used in the first part of the model to evaluate and determine the weights of the criteria. As the evaluation of the criteria is performed by several decision-makers (stakeholders' representatives), the Delphi method was used to consolidate their evaluations. The fuzzy VIKOR method was used in the second part of the model to evaluate, rank, and select the most favorable alternative in relation to the defined criteria.

The FARE method was developed by Ginevičius [25], and it is based on defining the relationship between all decisionmaking elements (criteria, subcriteria). In the first phase of the application, the method requires a minimum amount of initial data (evaluations) by the experts on the existence of influences between individual decision-making elements, as well as their direction and strength [26]. In later phases, the influences between other elements of decision-making are analytically determined on the basis of these evaluations. In this way, there is a drastic reduction in the required evaluations by experts [27]. The main advantages of the method, compared to the other methods based on the pairwise comparison of decision-making elements, e.g., AHP and ANP, are a small number of necessary evaluations, elimination of contradictions that occur in the comparison matrices, high reliability, consistency, and stability of the obtained results, etc. [26-28]. Due to the stated advantages, FARE was chosen in this paper for evaluation and determination of the criteria weights. However, as with other methods based on expert evaluation, the problem may arise due to ambiguous or unclear assessments, which can be solved by applying fuzzy logic. Therefore, the fuzzy extension of the FARE method, performed by Roy et al. [29], was used in the paper. The FARE method has found wide application in the literature and has so far been used, either alone or in a combination with other methods, either in conventional form or in the fuzzy environment, in various areas for evaluation and selection of 3PL providers [29], selection of production materials [30], evaluation of mechanical processes [27], evaluation of the impact of technology transfer on the value creation [31], selection of political candidates [5], evaluation of visibility in freight vehicles [32], etc.

The Delphi method was developed by Dalkey and Helmer [33] and is generally used to iteratively process decisionmakers' opinions until a consensus is reached on the subject of the research [34]. The method is defined as a process of group communication in which the convergence of opinions on a specific real-life problem is achieved. It is suitable for forming consensus through a series of questionnaires which in several iterations collect data from a group of selected respondents (experts). The main advantages of the method 
are anonymity, iteration, controlled feedback, statistical group responses, and stability in the decisions of decisionmakers on a given topic [35]. The main disadvantages of the method are the need for multiple repetitions of the questionnaire in order to achieve convergence of evaluations and high costs of data collection, especially for large and complicated problems and ambiguity and uncertainty in the assessment by experts $[35,36]$. One way to overcome these shortcomings is to extend the Delphi method to the fuzzy environment, which was performed by Murry et al. [37]. The Delphi method, alone or in combination with other methods, in conventional form or in the fuzzy environment, has been used in various fields to evaluate renewable energy development projects [38], locate terminals [39, 40], select plant layout [41], define typical structures of intermodal terminals [42], evaluate battery storage systems [43], plan intermodal terminals [44], etc.

The VIKOR method was developed by Opricovic [45] and is based on the ranking and selection of alternatives in relation to numerous, in most cases conflicting, and mutually incomparable decision-making criteria and determines a compromise solution to the problem. The obtained compromise solution can be accepted by the decision-maker because it achieves the majority maximum group utility and minimum individual regret of the opposing parties. The main advantages over other methods most commonly used to rank alternatives, e.g., ELECTRE, PROMETHEE; TOPSIS, etc., are stability, simplicity in the use of cardinal information, obtaining a unique solution, obtaining the final order of alternatives, obtaining the solution that is closest to the ideal solution, etc. [46-49]. As with the previous methods, one of the biggest problems of the conventional VIKOR method is the impossibility of adequate perception of inaccuracies in the evaluations of decision-makers, which is solved by applying fuzzy logic. The fuzzy extension of the VIKOR method was performed by Opricovic [50]. The VIKOR method is very popular and has been widely used in the literature in various areas for machine tool selection [51], evaluation of sustainable city logistics initiatives [52], health services [53], intermodal transport technology [54], risk management projects [55], CL conceptions [56], etc.

There are no examples in the literature of combining the FARE method with Delphi or VIKOR methods, either in conventional form or in the fuzzy environment. Accordingly, the development of a novel MCDM model that combines these three methods in the fuzzy environment is one of the main contributions of this paper.

\subsection{Last Mile Solution Sustainability. Based on different} initiatives, measures, technologies, concepts, approaches, etc., a large number of practical solutions can be defined in $\mathrm{CL}$, and even within a single solution, it is possible to define several different scenarios [57]. CL solutions are not universal-solutions that are proven good for particular urban areas can perform significantly worse in others $[56,58,59]$. The key to finding high-quality solutions for CL problems is in the compromise between the goals of stakeholders as well as in the balance among the identified demands and available resources [60]. A portion of the existing literature research focused on the selection of adequate last mile delivery solutions from a set of individual technologies and measures (e.g., [61-63]). Some research focused on the selection of the most appropriate initiatives from the defined CL initiative groups (e.g., [64, 65]). Most of the existing research focused on individual initiatives and technologies, but there are also examples that analyzed more complex CL solutions, defined by combining different initiatives, measures, and technologies.

The paper [66] analyzed the application of different drone-based CL solutions through a wider set of CL performances. The paper highlights that multiechelon CL solutions can achieve sustainability but require the definition of appropriate regulatory frameworks, especially for the application of autonomous vehicle technologies. Different CL solutions that take into account specific characteristics of the city and the environment are analyzed in the paper [56]. The goal was to find the best CL solution for the City of Belgrade for all stakeholders, but with regard to all the factors that describe the urban area. The solutions combined different categories of logistics centers, the concepts of consolidation, and the application of environment-acceptable transportation technologies. The problem of selecting the most appropriate solution for the logistics system in the central business district of Belgrade is solved in [67]. Different multiechelon systems, with different consolidation levels and the application of different transport technologies, are taken into account. The paper in [68] focused on the selection of the most appropriate CL solution for the City of Brussels where different configurations of urban consolidation centers and their combination with several vehicle categories, toll charging, and time access restrictions are taken into account. The selection of the most appropriate horizontal cooperation model between urban consolidation centers for the City of Bucharest is covered in the paper [69], while the paper in [70] analyzes the sustainability of the urban consolidation center in Copenhagen in scenarios that vary according to the measures of access restrictions for commercial vehicles, toll charging, and the number of public sector subsidies. In the paper [71], a last mile delivery solution that combines parcel lockers and electro-powered cargo cycles is analyzed for the case of Hannover.

A review of the most analyzed initiatives, technologies, and concepts of CL, as well as some of the new ones that stand out as the potential future solutions, is presented in Table 1.

The presence of multiple stakeholders, with often conflicting goals, gives a multicriterial dimension to the problems of selecting the most appropriate CL solutions [129]. Various criteria can be defined for solving CL problems, and those most widely used are presented in Table 2.

There are no papers in the literature that deal with defining innovative and complex sustainable solutions for the realization of the last mile, nor their evaluation by applying a wide set of criteria. This is done below on a real-life example and represents one of the main contributions of this paper. 
TABLE 1: Review of CL initiatives, concepts, and technologies.

\begin{tabular}{|c|c|c|}
\hline Initiative/technology/concept & Type & Literature \\
\hline Cooperation & - & {$[72,73]$} \\
\hline \multirow{2}{*}{ Consolidation } & Urban consolidation centers & {$[69,70,74-76]$} \\
\hline & Microconsolidation & {$[77,78]$} \\
\hline Crowdsourcing & - & {$[79-86]$} \\
\hline \multirow[t]{2}{*}{ Inland waterway transport } & - & {$[87-90]$} \\
\hline & Regular tram lines & [91-93] \\
\hline \multirow{2}{*}{ Rail transport } & Integrated rail systems & [94] \\
\hline & Cargo-hitching & {$[95,96]$} \\
\hline \multirow[t]{4}{*}{ Parcel lockers } & - & {$[71,97-100]$} \\
\hline & Electric & [101] \\
\hline & Hydrogen & {$[102]$} \\
\hline & Hybrid & {$[103]$} \\
\hline \multirow[t]{4}{*}{ Eco-vehicles } & Cargo bicycles & [104-107] \\
\hline & Cargo bikes & {$[108,109]$} \\
\hline & Scooters & {$[110]$} \\
\hline & Rickshaws & {$[111]$} \\
\hline \multirow{2}{*}{ Autonomous vehicles } & Ground autonomous vehicles & {$[112-115]$} \\
\hline & Aerial autonomous vehicles (drones) & {$[66,112,116-123]$} \\
\hline Underground logistics systems & - & [124-129] \\
\hline
\end{tabular}

TABLE 2: Relevant criteria review.

\begin{tabular}{|c|c|c|}
\hline Criteria group & Criteria & References \\
\hline Technical & $\begin{array}{c}\text { Efficiency (loading factor, trip effectiveness, volume of goods handled) } \\
\text { Reliability, flexibility, customer coverage } \\
\text { Service quality, service level, delivery time } \\
\text { Possibility of implementation, operative barriers, issues related to the lack of } \\
\text { infrastructure } \\
\text { Modal split of transport work } \\
\text { Goods flow transformation degree } \\
\text { Traceability, Information security }\end{array}$ & $\begin{array}{c}{[61,62,65,66,129]} \\
{[61,64,65]} \\
{[56,57,61-63,65-67,69,129]} \\
{[56,62]} \\
{[56,66]} \\
{[56,66,67]} \\
{[62]}\end{array}$ \\
\hline Economic & $\begin{array}{c}\text { Costs (operational, implementation, land and equipment acquisition, staff training, } \\
\text { insurance, taxes) }\end{array}$ & {$[56,57,61-68,70,129]$} \\
\hline Social & $\begin{array}{l}\text { Freeing of public space, consistency with urban planning, the attractiveness of the city } \\
\text { zone } \\
\text { Congestions, vibrations, noise, safety, mobility } \\
\text { Cooperation of stakeholders } \\
\text { Accessibility }\end{array}$ & $\begin{array}{c}{[56,61,64,65,67,68]} \\
{[56,57,61,63-65,67,68,129]} \\
{[62]} \\
{[61,64,65,129]}\end{array}$ \\
\hline Environmental & Air pollution, energy conservation, waste generation & {$[56,57,61,64-68,70,129]$} \\
\hline
\end{tabular}

\section{Proposed Hybrid MCDM Model}

For solving the problem of evaluating the sustainable LMSs, a novel hybrid MCDM model was developed in this paper that combines the fuzzy Delphi-based fuzzy FARE and the fuzzy VIKOR method. The structure of the proposed model is presented in Figure 1, while the steps of the model, which is universally applicable and which can, after minimal adjustments, be used to solve the problems in different areas, are described in detail as follows:

Step 1: define the problem structure; i.e., form the sets of alternatives and criteria for their evaluation and identify the stakeholders interested in solving the problem.

Step 2: define the fuzzy scale for the evaluations of criteria and alternatives by the decision-makers.
Linguistic evaluations and corresponding triangular fuzzy values are presented in Table 3.

Step 3: obtain the criteria weights by applying the fuzzy Delphi-based fuzzy FARE method. Also we have the following:

Step 3.1: form the criteria evaluation matrices $\widetilde{A}_{h}$ based on the linguistic evaluations by the decisionmakers that represent various stakeholders, and transform them into triangular fuzzy values using the relations given in Table 3:

$$
\widetilde{A}_{h}=\left[\widetilde{a}_{i j h}\right]_{n \times n}, \quad \forall h=1, \ldots, p,
$$

where $\tilde{a}_{i j h}=\left(l_{h}, m_{h}, u_{h}\right)$ is the evaluation of the strength of impact (importance) of the criterion $i$ in relation to the criterion $j$ by the decision-maker $h, l_{h}$, 


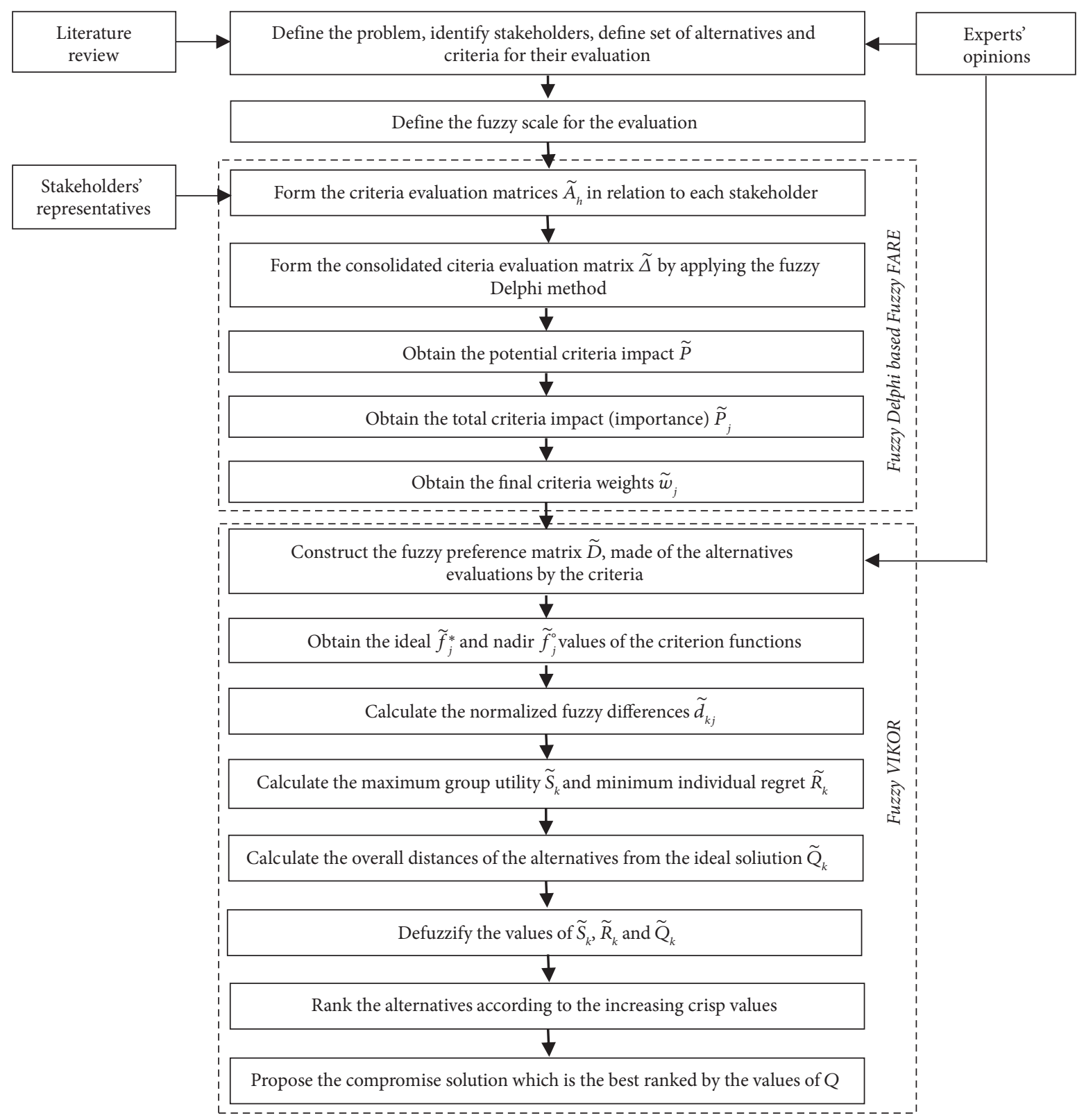

FIGURE 1: Structure of the proposed MCDM model. The model consists of two main parts, Fuzzy Delphi-based fuzzy FARE for obtaining criteria weights and fuzzy VIKOR for ranking the alternatives.

TABLE 3: Fuzzy scale from the evaluations.

\begin{tabular}{lcc}
\hline Linguistic evaluation & Abbreviation & Fuzzy scale \\
\hline None & $\mathrm{N}$ & $(1,1,2)$ \\
Very low & $\mathrm{VL}$ & $(1,2,3)$ \\
Low & $\mathrm{L}$ & $(2,3,4)$ \\
Fairly low & $\mathrm{FL}$ & $(3,4,5)$ \\
Medium & $\mathrm{M}$ & $(4,5,6)$ \\
Fairly high & $\mathrm{FH}$ & $(5,6,7)$ \\
High & $\mathrm{H}$ & $(6,7,8)$ \\
Very high & $\mathrm{VH}$ & $(7,8,9)$ \\
Extremely high & $\mathrm{EH}$ & $(8,9,10)$ \\
\hline
\end{tabular}

$m_{h}$, and $u_{h}$ are lover, middle, and upper values of the triangular fuzzy evaluation $\widetilde{a}_{i j h}, n$ is the number of criteria taken into account, and $p$ is the number of decision-makers performing the evaluations. When forming the matrix $\widetilde{A}_{h}$ the following condition must be met: 


$$
\tilde{a}_{j i h}=-\tilde{a}_{i j h},
$$

and the evaluation is considered consistent if the following is fulfilled:

$$
\sum_{j=1}^{n} u_{h}=-\sum_{j=1}^{n} l_{h}, \quad \forall h=1, \ldots, p .
$$

Step 3.2: form the consolidated criteria evaluation matrix $\widetilde{\Delta}$ by applying the fuzzy Delphi method [130]:

$$
\begin{aligned}
& \widetilde{\Delta}=\left[\widetilde{\delta}_{i j}\right]_{n \times n^{\prime}} \\
& \widetilde{\delta}_{i j}=(\alpha, \beta, \gamma), \\
& \alpha=\min \left(l_{h}\right), \quad h=1, \ldots, p, \\
& \beta=\left(\prod_{h=1}^{p} m_{h}\right)^{1 / p}, \quad h=1, \ldots, p, \\
& \gamma=\max \left(u_{h}\right), \quad h=1, \ldots, p,
\end{aligned}
$$

where $\alpha, \beta$, and $\gamma$ are lower, middle, and upper values of consolidated fuzzy evaluation $\widetilde{\delta}_{i j}$, respectively, and $\alpha \leq \beta \leq \gamma$.

Step 3.3: obtain the potential criteria impact in the following way:

$$
\widetilde{P}=\widetilde{H}(n-1),
$$

where $\widetilde{P}$ is the potential impact (importance) of all criteria for the defined problem, and $\widetilde{H}$ is the highest value of the scale used for the evaluations.

Step 3.4: obtain the total impact (importance) of criterion $\widetilde{P}_{j}$ by applying the following equation:

$$
\widetilde{P}_{j}=\sum_{i=1}^{n} \widetilde{\delta}_{i j}, \quad \forall j=1, \ldots, n, j \neq i .
$$

Step 3.5: obtain the final fuzzy criteria weights $\widetilde{w}_{j}$ by applying the following equation:

$$
\widetilde{w}_{j}=\frac{\widetilde{P}_{j}^{r}}{\widetilde{P}_{H}}, \quad \forall j=1, \ldots, n,
$$

where $\widetilde{P}_{H}$ is the total potential impact (importance) of the considered set of criteria obtained in the following way:

$$
\widetilde{P}_{H}=n \times \widetilde{P}
$$

and $\widetilde{P}_{j}^{r}$ is the real total impact of the criterion $j$ obtained in the following way:

$$
\widetilde{P}_{r}^{j}=\widetilde{P}_{j}+\widetilde{P}, \quad \forall j=1, \ldots, n,
$$

Step 4: evaluate the alternatives by applying the fuzzy VIKOR method. The procedure is adapted from the paper [131], and the steps are described as follows.

Step 4.1: construct the fuzzy preference matrix $(\widetilde{D})$. It is necessary to perform the evaluation of the alternatives (LMSs), in relation to the criteria using the triangular fuzzy values given in Table 3:

$$
\widetilde{D}=\left[\widetilde{f}_{k j}\right]_{o \times n}
$$

where $\tilde{f}_{k j}=\left(l_{k j}, m_{k j}, u_{k j}\right)$ denotes triangular fuzzy evaluations of the alternative $k$ in relation to the criterion $j . o$ is the total number of alternatives taken into consideration.

Step 4.2: obtain the ideal $\widetilde{f}_{j}^{*}=\left(l_{j}^{*}, m_{j}^{*}, u_{j}^{*}\right)$ and nadir $\widetilde{f}_{j^{\circ}}=\left(l_{j}^{\circ}, m_{j}^{\circ}, u_{j}^{\circ}\right)$ values of all criterion functions which represent the evaluations of the alternatives by the criteria depending on whether they are the benefit or cost criteria. The set of benefit criteria is denoted as $J^{b}$, while the set of cost criteria is denoted as $J^{c}$.

$$
\begin{gathered}
\tilde{f}_{j}^{*}=\max _{k} \tilde{f}_{k j}, \quad \tilde{f}_{j^{\circ}}=\min _{k} \tilde{f}_{k j}, \quad \text { for } j \in J^{b}, \\
\tilde{f}_{j}^{*}=\min _{k} \tilde{f}_{k j}, \quad \tilde{f}_{j}^{\circ}=\max _{k} \tilde{f}_{k j}, \quad \text { for } j \in J^{c} .
\end{gathered}
$$

Step 4.3: calculate the normalized fuzzy differences $\widetilde{d}_{k j}$ :

$$
\tilde{d}_{k j}=\frac{\tilde{f}_{j}^{*} \ominus \widetilde{f}_{k j}}{u_{j}^{*}-l_{j^{\circ}}}, \text { for } j \in J^{b} \widetilde{d}_{k j}=\frac{\widetilde{f}_{k j} \ominus \tilde{f}_{j}^{*}}{u_{j^{\circ}}-l_{j}^{*}} \text { for } j \in J^{c} .
$$

Step 4.4: calculate the values of $\widetilde{S}_{k}=\left(S_{k}^{l}, S_{k}^{m}, S_{k}^{u}\right)$, representing the normalized fuzzy difference, i.e., maximum group utility, and the values of $\widetilde{R}_{k}=\left(R_{k}^{l}, R_{k}^{m}, R_{k}^{u}\right)$ representing the maximum fuzzy difference, i.e., minimum individual regret, by applying the following equations:

$$
\begin{aligned}
& \widetilde{S}_{k}=\sum_{j=1}^{n} \widetilde{w}_{j} \otimes \widetilde{d}_{j k}, \\
& \widetilde{R}_{k}=\max _{j} \widetilde{w}_{j} \otimes \widetilde{d}_{j k} .
\end{aligned}
$$

Step 4.5: calculate the values of $\widetilde{Q}_{k}=\left(Q_{k}^{l}, Q_{k}^{m}, Q_{k}^{u}\right)$, i.e., the overall distances of the alternatives from the ideal solution, by applying the following equation:

$$
\widetilde{Q}_{k}=v \frac{\widetilde{S}_{k} \ominus \widetilde{S}^{*}}{S^{\text {ou }}-S^{* l}} \oplus(1-v) \frac{\widetilde{R}_{k} \ominus \widetilde{R}^{*}}{R^{\text {ou }}-R^{* l}},
$$

where $\widetilde{S}^{*}=\min _{k} \widetilde{S}_{k}, S^{* l}$ is the lower value of the triangular fuzzy number $\widetilde{S}^{*}, S^{\mathrm{ou}}=\max _{k} S_{k}^{u}, \widetilde{R}^{*}=\min _{k} \widetilde{R}_{k}$, $R^{* l}$ is the lower value of the triangular fuzzy number $\widetilde{R}^{*}$, and $R^{\text {ou }}=\max _{k} R_{k}^{u}$. Value $v$ refers to the weight of the strategy of "the majority of criteria" (or "the maximum group utility"), whereas $1-v$ is the weight of the individual regret. 
Step 4.6: defuzzify the values of $\widetilde{S}_{k}, \widetilde{R}_{k}$, and $\widetilde{Q}_{k}$ using the following equation [132]:

$$
\operatorname{crisp}(\widetilde{T})=\frac{\left(T^{l}+4 T^{m}+T^{u}\right)}{6},
$$

where $\widetilde{T}=\left(T^{l}, T^{m}, T^{u}\right)$ is any triangular fuzzy number.

Step 4.7: rank the alternatives (LMSs), according to the increasing crisp values. The results are three ranking lists $\{\mathrm{LMS}\}_{S},\{\mathrm{LMS}\}_{R}$, and $\{\mathrm{LMS}\}_{\mathrm{Q}}$ according to $\operatorname{crisp}(S), \operatorname{crisp}(R)$, and $\operatorname{crisp}(Q)$, respectively.

Step 4.8: propose as a compromise solution the alternative LMS ${ }^{(1)}$ which is the best ranked by the values of $Q$, if the following two conditions are satisfied:

Co.1. "Acceptable Advantage": Adv $\geq D Q$ where Adv = $\left[Q\left(\operatorname{LMS}^{(2)}\right)-Q\left(\operatorname{LMS}^{(1)}\right)\right] /\left[Q\left(\operatorname{LMS}^{(o)}\right)-Q\left(\operatorname{LMS}^{(1)}\right)\right]$ is the advantage rate of the alternative $\mathrm{LMS}^{(1)}$, ranked as the first, in relation to the alternative $\operatorname{LMS}^{(2)}$, ranked as the second one in the list $\{\mathrm{LMS}\}_{Q}$, and $D Q=1 /(o-1)$ represents the threshold from which the advantage rate (Adv) has to be higher.

Co.2. "Acceptable Stability in decision-making": Alternative LMS $^{(1)}$ must also be the best ranked by $S$ and/ or $R$.

If one of the conditions is not satisfied, then a set of compromise solutions is proposed, which consists of the following:

CS1. Alternatives $\mathrm{LMS}^{(1)}$ and $\mathrm{LMS}^{(2)}$ if only the condition Co.2 is not satisfied

CS2. Alternatives $\operatorname{LMS}^{(1)}, \mathrm{LMS}^{(2)}, \ldots, \mathrm{LMS}^{(M)}$ if the condition Co.1 is not satisfied; $\operatorname{LMS}^{(M)}$ is determined by the relation $\left[Q\left(\mathrm{LMS}^{(M)}\right)-Q\left(\mathrm{LMS}^{(1)}\right)\right] /\left[Q\left(\mathrm{LMS}^{(o)}\right)-\right.$ $\left.Q\left(\operatorname{LMS}^{(1)}\right)\right]<D Q$ for maximum $M$ (the positions of these alternatives are "in closeness")

\section{Evaluation of the Sustainable Last Mile Solutions}

For solving the problem of evaluating the sustainable LMS, a novel hybrid MCDM model was developed in this paper that combines the fuzzy Delphi-based fuzzy FARE and the fuzzy VIKOR method. The structure of the proposed model is presented in Figure 1.

4.1. Proposed Sustainable Last Mile Solutions for the Central Business District of Belgrade. By combining the reviewed initiatives and technologies, it is possible to define a wide set of solutions, but only those that are applicable and in line with the principles of sustainability are taken into consideration (Figure 2). It is assumed that the concepts of cooperation and flow consolidation at the outskirts of urban areas are an integral element of logistics in the city; therefore, they are not explicitly highlighted in the description of the analyzed LMSs. All proposed solutions also include two freight villages (FVs) whose development is planned at the outskirts of Belgrade.
The first solution $\left(L M S_{1}\right)$ is a combination of the ideas of parcel lockers and crowdsourcing (Figure 2(a)). Goods delivery from FVs to parcel lockers, located in the immediate proximity of the end users, is performed with the road freight vehicles. Flow generators independently collect their goods at the assigned parcel lockers, where they can obtain discounts/benefits/financial compensation by taking the role of crowd agents and delivering the goods to the other generators in their surroundings. By utilizing parcel lockers, the providers are relieved of the responsibilities in the last phase of the delivery, and at the same time, the uncertainties that exist in the classic crowdsourcing models are reduced. The implementation of this solution requires the deployment of parcel lockers in the central business district and the development of the software platform used for the communication between logistics providers and crowd agents. The required investments for the development of $\mathrm{LMS}_{1}$ are relatively low, but delivery reliability is problematic due to the crowd agents' autonomy.

The solution $\mathrm{LMS}_{2}$ considers the development of microconsolidation centers in the delivery zone which enables the modal shift of transport work on autonomous vehicles (Figure 2(b)). Goods delivery from FVs to microconsolidation centers is performed with road freight vehicles, while the last phase is performed with ground autonomous vehicles and drones. This solution requires the development of logistics infrastructure (microconsolidation centers) in the central business district and the definition of regulatory frameworks for the application of autonomous vehicles. By transforming the delivery system into a twophased system, efficiency and reliability are improved while negative environmental impacts are reduced. On the other hand, the application of autonomous technologies requires the definition of specific regulations and opens a wide variety of questions, especially those regarding safety.

The third solution $\left(\mathrm{LMS}_{3}\right)$ also performs the delivery through two phases, but with road freight vehicles in the role of mobile depots, where the last phase of the delivery is performed with drones (Figure 2(c)). Road freight vehicles visit convenient locations (special parking slots) near flow generators from where the drones are launched to execute the last delivery phase. This solution requires the synchronization between ground vehicles and drones in the delivery process and also the adoption of regulations that would define the application of drones in urban areas. Besides, drone-based delivery is sensitive to unfavorable weather conditions (strong wind, rain, and storm) that are present during the winter months in the City of Belgrade.

The solution $\mathrm{LMS}_{4}$ delivers goods from FVs to the central business district with rail transportation (regular cargo tram lines), where the last phase of the delivery is performed with light commercial vehicles-cargo bicycles and scooters (Figure 2(d)). The solution utilizes the existing infrastructure, but to improve the flexibility of the solution, the transportation of goods outside regular time schedules is made possible through the idea of cargo-hitching (with regular passenger tram lines). This solution greatly eliminates road transportation and improves the logistics system's efficiency by redistributing the transport work on rail 


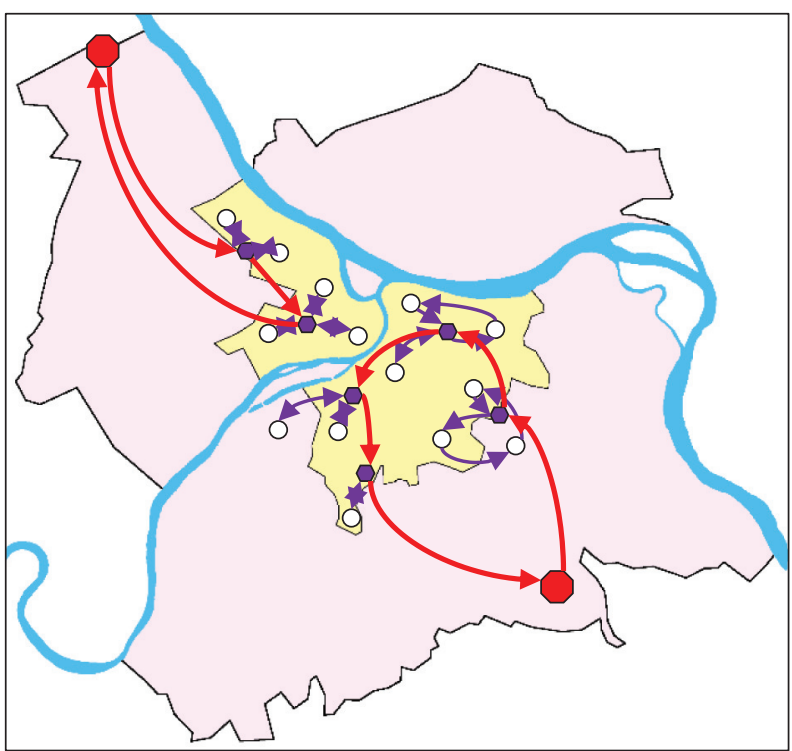

-freight village

O -flow generator (end consumer)

$\rightarrow$-commercial vehicle route

(a)

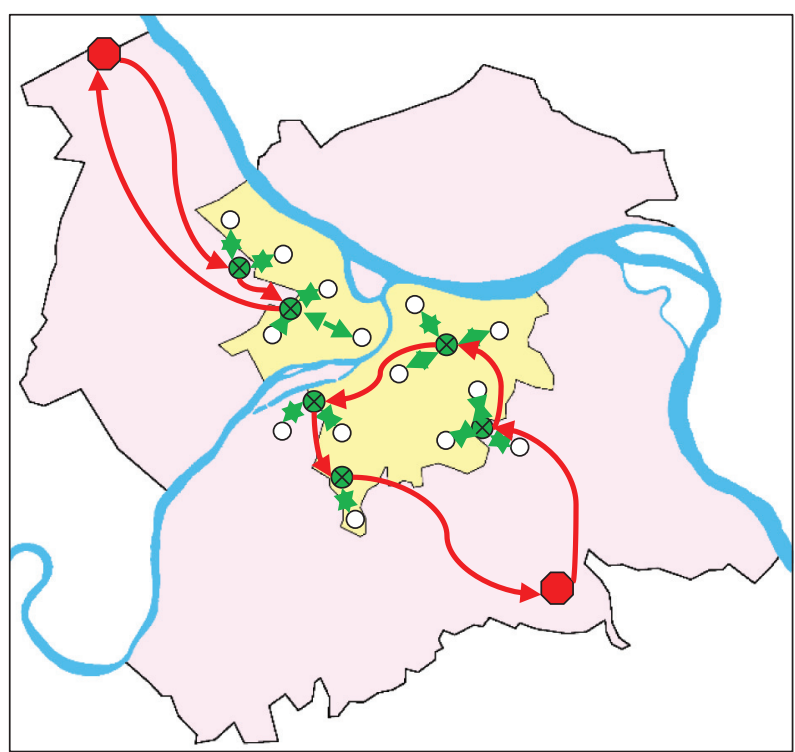

-freight village

-flow generator (end consumer)

$\rightarrow$-commercial vehicle route

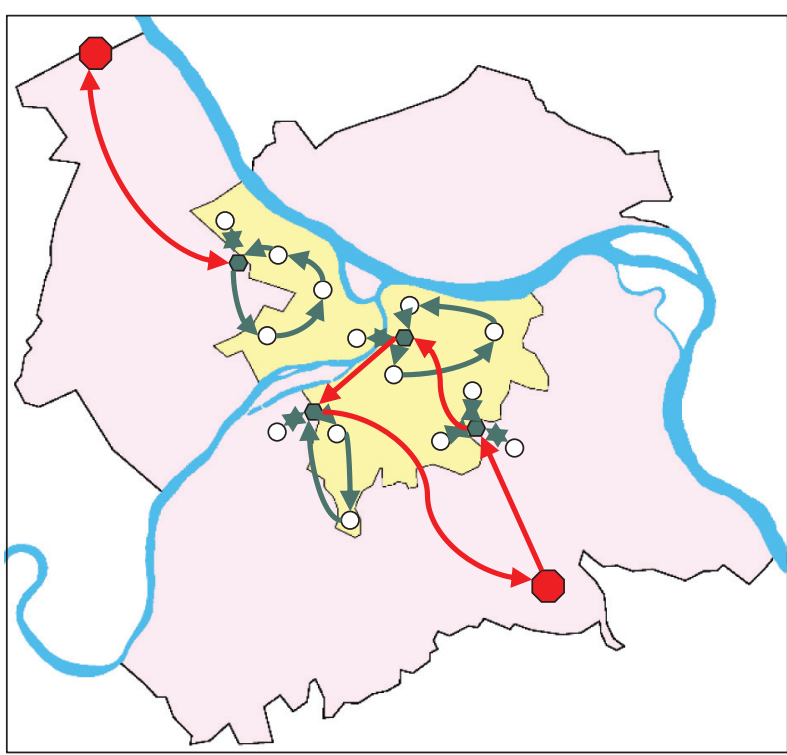

-freight village

-flow generator (end consumer)

$\rightarrow$-commercial vehicle route

$\leftrightarrow$-drone route

$\rightarrow$-autonomous ground vehicle route

- micro-consolidation centre

(b)

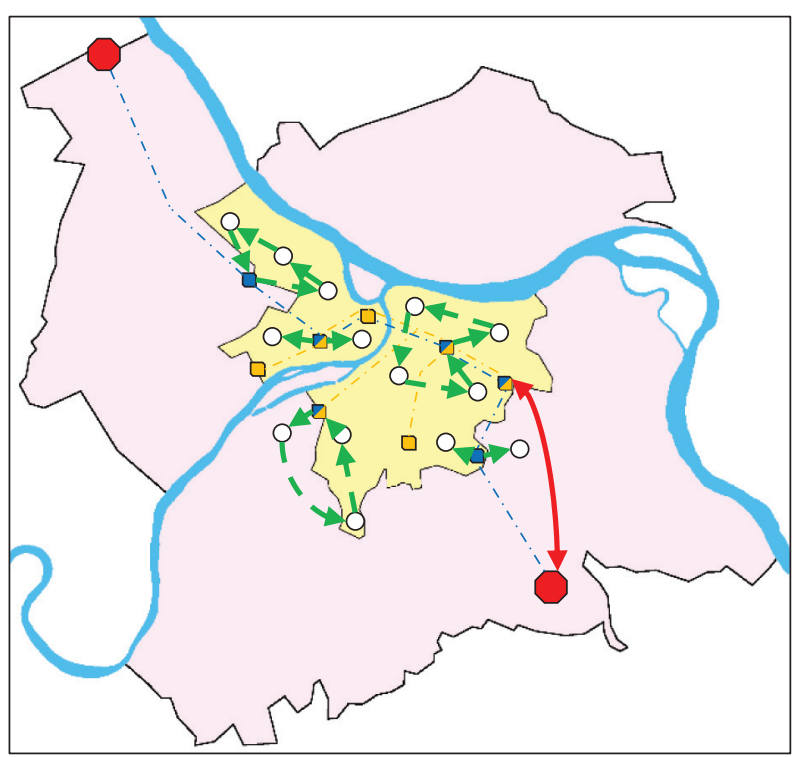

- cargo transhipment station passenger tram route

$\checkmark$ passenger tram station

v combined station

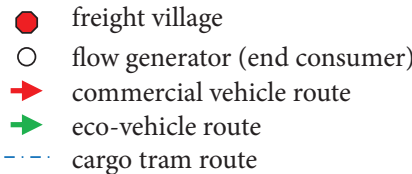

(c)

Figure 2: Continued. 


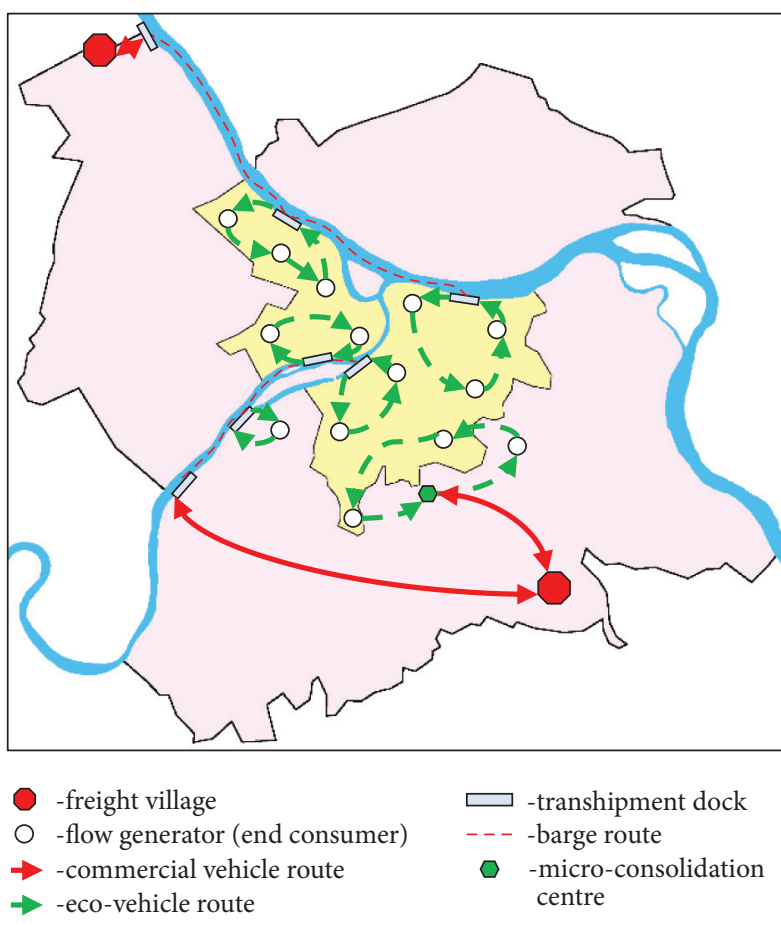

(e) $\rightarrow$-commercial vehicle rout $\rightarrow$-eco-vehicle route -micro-consolidation
centre

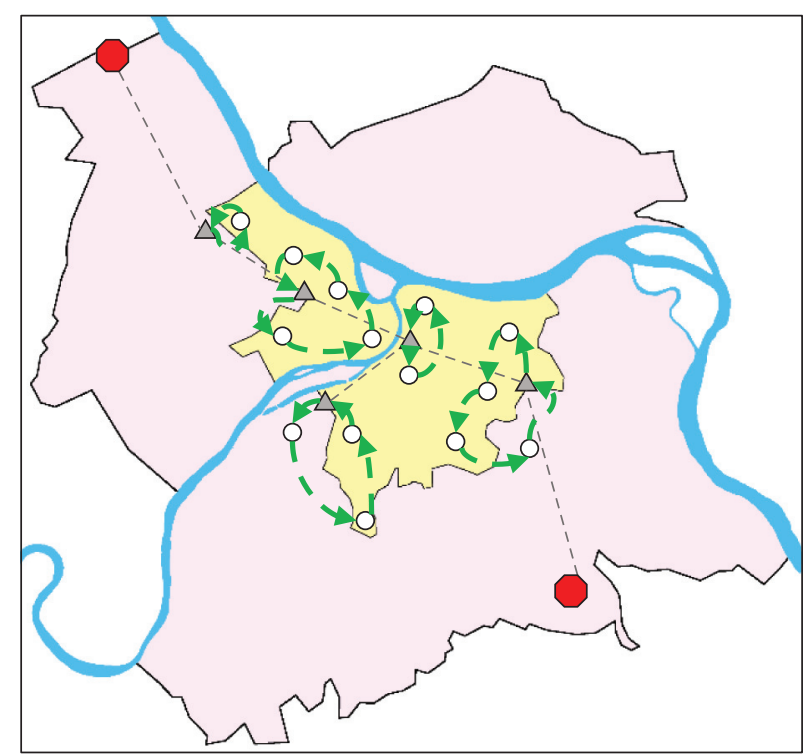

-freight village

$\bigcirc$-flow generator (end consumer) --- - -underground connection $\rightarrow$-commercial vehicle route

(f)

Figure 2: Last mile delivery solutions for the central business district of Belgrade. Six different solutions are created, namely, (a) LMS ${ }_{1}$, (b) $\mathrm{LMS}_{2}$, (c) $\mathrm{LMS}_{3}$, (d) $\mathrm{LMS}_{4}$, (e) $\mathrm{LMS}_{5}$, and (f) $\mathrm{LMS}_{6}$.

transportation. The weakness of this solution is its operational complexity, the demand for installing transshipment stations in the central business district, the general nonflexibility of rail transportation, and mixing passenger and goods flows through the concept of cargo-hitching.

In the solution $\mathrm{LMS}_{5}$, inland waterways of the rivers Sava and Danube are used for the transportation of goods to the central business district of Belgrade (Figure 2(e)). Along the riverbeds, transshipment stations that enable the transfer of goods on eco-delivery vehicles (bikes, cycles, and smaller electrovehicles) are located. Goods transportation between FVs and the nearest transshipment stations is performed with the road shuttle connections. This solution eliminates road freight transportation in coastal urban areas, but some locations remain outside the delivery zone of transshipment stations. To provide service for these locations, the development of microconsolidation centers in particular urban zones is required. Goods delivery to microconsolidation centers is performed with road freight vehicles, from where the last phase of the delivery is performed with eco-vehicles. The solution utilizes the natural infrastructural resources-inland waterways-but requires the development of additional infrastructure-coastal transshipment stations and microconsolidation centers. Although this solution improves the efficiency of logistics activities, inland waterway transportation is generally nonflexible and sensitive on unfavorable weather conditions.

The solution $\mathrm{LMS}_{6}$ refers to the utilization of an underground logistics system for goods transportation between FVs and the central business district (Figure 2(f)). Since the
City of Belgrade is characterized by significant spatial dispersion of generators, it is impossible to include all generators in an underground system. Instead, transshipment stations that enable the modal shift on light freight vehicles-bikes, bicycles, scooters, and electrovehicles-used in the last delivery phase, are developed on strategically important locations. Underground logistics systems reduce negative environmental impacts of logistics and improve mobility in urban areas. On the other hand, the solution generates high infrastructural investments, and the development of underground systems is not even possible in historical parts of the city. Aside from the aforementioned, this solution can be the key to achieving logistics sustainability in city areas that are yet to be constructed.

4.2. Criteria for the Evaluation of the Last Mile Solutions. For the evaluation of the LMSs for the central business district of Belgrade, ten criteria are defined and explained in the following text. The criteria are selected according to the literature review, analysis of the CL participants in Belgrade, and the authors' experience in the field.

Efficiency $\left(C_{1}\right)$ represents the rationalization level of logistics activities within a solution. It refers to the utilization of loading space in commercial vehicles, the average traveled distance per delivery, overall delivery completion times, fuel and energy consumption, etc.

Operation complexity of delivery $\left(C_{2}\right)$ depends on the goods flow transformation degree and the applied technologies. In solutions that transform the logistics system into 
multiechelon systems, with or without transportation modal shift, the complexity of delivery operations is higher.

Flexibility $\left(C_{3}\right)$ refers to the possibility of the logistics system's adaptation to unexpected changes in demand characteristics. The solutions that imply the use of rail and inland waterway transportation have lower flexibility, while the solutions that rely more on road transportation are more flexible.

Reliability $\left(C_{4}\right)$ refers to the availability of services and goods in acceptable time intervals. Solutions with systems whose activity execution greatly depends on weather conditions (barges and drones) and traffic conditions are less reliable because of frequent delays and bottlenecks.

Implementation possibility $\left(C_{5}\right)$ of a solution refers to its compatibility with existing urban plans for the observed area. This criterion also reflects on the need for defining new laws, regulations, and measures that cover the application of newer delivery technologies (such as drones and autonomous vehicles), as well as on the administrative procedures that precede the implementation of such solutions.

Implementation costs $\left(C_{6}\right)$ refer to the number of infrastructural investments required for the development and implementation of an LMS.

Modal redistribution of transport work $\left(C_{7}\right)$ implies the stimulation (subsidies) for the use of alternative transportation means (rail, inland waterway, or drones) in the LMSs.

Freeing of public space $\left(C_{8}\right)$ describes to what level the solution contributes to the freeing of public spaces (roads, sidewalks, plazas, promenades, parks, green areas, lots, etc.) for the development of more attractive content.

Environmental impact $\left(C_{9}\right)$ refers to the reduction of logistics activities' negative environmental impact-airpollutant emissions and ecosystem degradation, which follow the implementation of modern LMSs.

Mobility $\left(C_{10}\right)$ refers to the conditions that enable the uninterrupted realization of goods and passenger flows in the urban areas. By reducing the participation of road transportation in overall transport, urban mobility rises.

4.3. Evaluation of the Last Mile Solutions. The first step in applying the model, in addition to defining a set of alternatives and criteria for their evaluation, involves identifying stakeholders interested in solving the problem. The evaluation of the criteria was performed from the aspect of four CL stakeholders: residents (Res.), users (Use.), logistics service providers (Pro.), and city administration (Adm.). Residents are people who live, work, and shop in the city. They strive to minimize traffic congestion, noise, air pollution, and traffic accidents near the place of residence, work, and shopping. Shippers and recipients are the users of the services who send or receive goods and generally require the provider to maximize the level of service, which means shorter delivery/collection times, greater reliability and flexibility, and better information at a lower cost of service. Providers strive to minimize the cost of collecting or delivering goods to customers, while maximizing profits. The city administration aims at economic development of the city and increasing employment opportunities on the one side and reducing traffic congestion, improving living conditions, and increasing traffic safety on the other [133]. In accordance with their preferences, stakeholders' representatives evaluated the importance of the criteria with linguistic assessments (Table 4).

By applying the relations given in Table 3, the evaluations were transformed to the fuzzy values, thus forming the criteria evaluation matrices (1), while satisfying conditions (2) and (3). For the matrices obtained in such way, the consolidated criteria evaluation matrix is formed by applying equations 4-(8). By applying equation (9), the potential criteria impact was calculated, and by applying equation (10), the total impact (importance) of criteria was determined. The final criteria weights were obtained by applying equations (11)-(13). The following criteria weights were obtained: $\left(\widetilde{w}_{1} ; \widetilde{w}_{2} ; \widetilde{w}_{3} ; \widetilde{w}_{4} ; \widetilde{w}_{5} ; \widetilde{w}_{6} ; \widetilde{w}_{7} ; \widetilde{w}_{8} ; \widetilde{w}_{9}\right.$; $\left.\widetilde{w}_{10}\right)=(0.050,0.102,0.200 ; 0.050,0.096,0.193 ; 0.050,0.100$, $0.197 ; 0.050,0.104,0.206 ; 0.051,0.103,0.198 ; 0.051,0.105$, $0.217 ; 0.050,0.092,0.167 ; 0.050,0.096,0.192 ; 0.050,0.097$, $0.198 ; 0.051,0.107,0.213$ ).

The evaluation of alternatives in relation to the criteria (Table 5) was performed in the next step. Evaluations were converted into fuzzy values using the relations given in Table 3, thus forming a fuzzy preference matrix (14). By applying equation (15), the ideal and nadir values of all criterion functions were obtained and then the normalized fuzzy differences by applying equation (16).

By applying equations (17) and (18), the values of maximum group utility and minimum individual regret were obtained, and then the overall distances of the alternatives from the ideal solution by applying equation (19) (value of 0.5 was taken for parameter $v$ ). These values were then defuzzified using equation (20), and the final ranking of the alternatives was performed. The results of the conducted ranking process are presented in Table 6.

$\mathrm{LMS}_{2}$ is selected as the best ranked alternative since it is ranked as the first one according to the $Q, S$, and $R$, thus satisfying the condition Co.2. The condition Co.1 is also satisfied since $\mathrm{Adv}=0.346 \geq D Q=0.200$.

4.4. Sensitivity Analysis. In order to examine the stability of the obtained solution, a sensitivity analysis was performed. Eight scenarios have been defined in which individual model parameters have been changed. In the first four scenarios (Sc.1-Sc.4), the ranking of alternatives was performed based on the criteria weights obtained by the evaluation of representatives of each stakeholder, namely, providers, users, administration, and residents, respectively. In the next three scenarios (Sc.5-Sc.7), one of the three most important criteria, $C_{10}, C_{6}$, and $C_{4}$, was excluded from the model, respectively. In the last scenario (Sc.8), all three most important criteria were excluded from the model. The obtained results of ranking by scenarios and changes in relation to the baseline scenario (Sc.0) are presented in Table 7, while the graphical representation of the sensitivity analysis is presented in Figure 3. 
TABle 4: Criteria evaluation by the stakeholders' representatives (Res., Use., Pro., and Adm.).

\begin{tabular}{|c|c|c|c|c|c|c|c|c|c|c|}
\hline & $C_{1}$ & $C_{2}$ & $C_{3}$ & $C_{4}$ & $C_{5}$ & $C_{6}$ & $C_{7}$ & $C_{8}$ & $C_{9}$ & $C_{10}$ \\
\hline$C_{1}$ & $(/, /, /, /)$ & $(\mathrm{FL}, \mathrm{VL}, /, \mathrm{L})$ & $(/, /, \mathrm{L}, \mathrm{VL})$ & $(/, /, \mathrm{L}, \mathrm{VL})$ & $(/, \mathrm{L}, \mathrm{FL}, /)$ & $\begin{array}{c}(\mathrm{VL}, \mathrm{L}, \mathrm{VL}, / \\
)\end{array}$ & $(\mathrm{FL}, \mathrm{H}, \mathrm{FH}, /)$ & $(/, \mathrm{FH}, \mathrm{EH}, /)$ & $(/, \mathrm{M}, \mathrm{EH}, /)$ & $(/, \mathrm{N}, \mathrm{H}, /)$ \\
\hline$C_{2}$ & $(/, /, \mathrm{N}, /)$ & $(/, /, /, /)$ & $(/, /, \mathrm{L}, /)$ & $(/, /, \mathrm{L}, /)$ & $\begin{array}{c}(/, \mathrm{VL}, \mathrm{FL}, / \\
)\end{array}$ & $(/, \mathrm{VL}, \mathrm{VL}, /)$ & $(/, \mathrm{FH}, \mathrm{FH}, /)$ & $(/, \mathrm{M}, \mathrm{EH}, /)$ & $(/, \mathrm{FL}, \mathrm{EH}, /)$ & $(/, /, \mathrm{H}, /)$ \\
\hline$C_{3}$ & $(\mathrm{~N}, \mathrm{~L}, /, /)$ & $\begin{array}{c}\text { (FL,FL,/ } \\
\text {,VL) }\end{array}$ & $(/, /, /, /)$ & $(/ / /, \mathrm{N}, /)$ & $(/, \mathrm{M}, \mathrm{VL}, /)$ & $(\mathrm{VL}, \mathrm{M}, /, /)$ & $(\mathrm{FL}, \mathrm{EH}, \mathrm{FL}, /)$ & $(/, \mathrm{VH}, \mathrm{H}, /)$ & $(/, \mathrm{H}, \mathrm{H}, /)$ & $(/, \mathrm{L}, \mathrm{M}, /)$ \\
\hline$C_{4}$ & $(\mathrm{FL}, \mathrm{L}, /, /)$ & $(\mathrm{H}, \mathrm{FL}, /, \mathrm{VL})$ & $(\mathrm{FL}, \mathrm{N}, / \mathrm{N})$ & $(/, /, /, /)$ & $\begin{array}{c}(\mathrm{L}, \mathrm{M}, \mathrm{VL}, / \\
)\end{array}$ & $(\mathrm{M}, \mathrm{M}, /, /)$ & $(\mathrm{H}, \mathrm{EH}, \mathrm{FL}, /)$ & $(/, \mathrm{VH}, \mathrm{H}, /)$ & $(/, \mathrm{H}, \mathrm{H}, /)$ & $(/, \mathrm{L}, \mathrm{M}, /)$ \\
\hline$C_{5}$ & $\begin{array}{l}(\mathrm{VL}, / \\
, /, \mathrm{M})\end{array}$ & $(\mathrm{M}, /, /, \mathrm{H})$ & $(\mathrm{VL}, /, /, \mathrm{FH})$ & $(/, l, l, \mathrm{FH})$ & $(/, /, /, /)$ & $(\mathrm{L}, \mathrm{N}, /, /)$ & $(\mathrm{M}, \mathrm{M}, \mathrm{L}, \mathrm{L})$ & $(/, F L, F H, V L)$ & $(/, \mathrm{L}, \mathrm{FH}, \mathrm{L})$ & $(/, /, \mathrm{FL}, \mathrm{N})$ \\
\hline $\begin{array}{l}C_{6} \\
C_{7}\end{array}$ & $\begin{array}{l}(/, /, /, \mathrm{H}) \\
(/, /, /, \mathrm{L})\end{array}$ & $\begin{array}{r}(\mathrm{L}, /, /, \mathrm{EH}) \\
(\mathrm{N}, /, /, \mathrm{M})\end{array}$ & $\begin{array}{c}(/, /, \mathrm{VL}, \mathrm{VH}) \\
(/, /, /, \mathrm{FL})\end{array}$ & $\begin{array}{c}(/, /, \mathrm{VL}, \mathrm{VH}) \\
(/, /, /, \mathrm{FL})\end{array}$ & $\begin{array}{c}(/, /, \mathrm{L}, \mathrm{L}) \\
(/, /, /, /)\end{array}$ & $\begin{array}{l}(/, /, /, /) \\
(/, /, /, /)\end{array}$ & $\begin{array}{c}(\mathrm{L}, \mathrm{M}, \mathrm{M}, \mathrm{M}) \\
(/, /, /, /)\end{array}$ & $\begin{array}{c}(/, \mathrm{FL}, \mathrm{VH}, \mathrm{FL}) \\
(/, /, \mathrm{FL}, /)\end{array}$ & $\begin{array}{c}(/, \mathrm{L}, \mathrm{VH}, \mathrm{M}) \\
(/, /, \mathrm{FL}, /)\end{array}$ & $\begin{array}{r}(/ /, \text { FH,L }) \\
(/ /, /, \mathrm{VL}, /)\end{array}$ \\
\hline$C_{8}$ & $(\mathrm{M}, / /, /, \mathrm{FL})$ & $(\mathrm{VH}, /, /, \mathrm{FH})$ & $(\mathrm{M}, / /, \mathrm{M})$ & $(\mathrm{VL}, /, /, \mathrm{M})$ & $(\mathrm{FL}, / /, /)$, & $(\mathrm{FH}, /, /, /)$ & $\begin{array}{c}\text { (VH,VL,/ } \\
\text {,VL) }\end{array}$ & $(/$, & VL) & $(I, /, /, /)$ \\
\hline$C_{9}$ & $(\mathrm{FH}, /, /, \mathrm{L})$ & $(\mathrm{EH}, /, /, \mathrm{M})$ & $(\mathrm{FH}, /, /, \mathrm{FL})$ & $(\mathrm{L}, / /, /, \mathrm{FL})$ & $(\mathrm{M}, /, /, /)$ & $(\mathrm{H}, /, /, /)$ & $(\mathrm{EH}, \mathrm{L}, /, \mathrm{N})$ & $(\mathrm{VL}, \mathrm{VL}, \mathrm{N}, /)$ & $(I, l, /, /)$ & $(/, /, /, /)$ \\
\hline$C_{10}$ & $\begin{array}{l}(\mathrm{FH}, / \\
, /, \mathrm{M})\end{array}$ & $\begin{array}{c}(\mathrm{EH}, \mathrm{VL}, / \\
\text {,H) }\end{array}$ & $(\mathrm{FH}, /, /, \mathrm{FH})$ & $(\mathrm{L}, /, /, \mathrm{FH})$ & $(\mathrm{M}, \mathrm{L}, / /, /)$ & $(\mathrm{H}, \mathrm{L}, /, /)$ & $(\mathrm{EH}, \mathrm{H}, /, \mathrm{L})$ & $(\mathrm{VL}, \mathrm{FH}, \mathrm{L}, \mathrm{VL})$ & $(\mathrm{N}, \mathrm{M}, \mathrm{L}, \mathrm{L})$ & $(/, /, /, /)$ \\
\hline
\end{tabular}

TABLE 5: Evaluation of the alternatives in relation to the criteria.

\begin{tabular}{lcccccccccc}
\hline & $C_{1}$ & $C_{2}$ & $C_{3}$ & $C_{4}$ & $C_{5}$ & $C_{6}$ & $C_{7}$ & $C_{8}$ & $C_{9}$ & $C_{10}$ \\
\hline LMS $_{1}$ & $\mathrm{~L}$ & $\mathrm{EH}$ & $\mathrm{VH}$ & $\mathrm{L}$ & $\mathrm{EH}$ & $\mathrm{EH}$ & $\mathrm{VL}$ & $\mathrm{H}$ & $\mathrm{L}$ & $\mathrm{VH}$ \\
$\mathrm{LMS}_{2}$ & $\mathrm{FH}$ & $\mathrm{VH}$ & $\mathrm{H}$ & $\mathrm{H}$ & $\mathrm{H}$ & $\mathrm{H}$ & $\mathrm{FH}$ & $\mathrm{FH}$ & $\mathrm{H}$ & $\mathrm{M}$ \\
$\mathrm{LMS}_{3}$ & $\mathrm{VL}$ & $\mathrm{H}$ & $\mathrm{EH}$ & $\mathrm{M}$ & $\mathrm{L}$ & $\mathrm{VH}$ & $\mathrm{L}$ & $\mathrm{H}$ & $\mathrm{VL}$ & $\mathrm{VL}$ \\
$\mathrm{LMS}_{4}$ & $\mathrm{H}$ & $\mathrm{M}$ & $\mathrm{FH}$ & $\mathrm{VH}$ & $\mathrm{VH}$ & $\mathrm{M}$ & $\mathrm{H}$ & $\mathrm{M}$ & $\mathrm{FH}$ & $\mathrm{FH}$ \\
$\mathrm{LMS}_{5}$ & $\mathrm{EH}$ & $\mathrm{VL}$ & $\mathrm{L}$ & $\mathrm{VL}$ & $\mathrm{FL}$ & $\mathrm{FH}$ & $\mathrm{EH}$ & $\mathrm{VH}$ & $\mathrm{EH}$ & $\mathrm{H}$ \\
$\mathrm{LMS}_{6}$ & $\mathrm{VH}$ & $\mathrm{FH}$ & $\mathrm{VL}$ & $\mathrm{EH}$ & $\mathrm{VL}$ & $\mathrm{VL}$ & $\mathrm{VH}$ & $\mathrm{EH}$ & $\mathrm{VH}$ & $\mathrm{EH}$ \\
\hline
\end{tabular}

TABLE 6: Final ranking of the alternatives.

\begin{tabular}{|c|c|c|c|c|c|c|c|}
\hline & & $\mathrm{LMS}_{1}$ & $\mathrm{LMS}_{2}$ & $\mathrm{LMS}_{3}$ & $\mathrm{LMS}_{4}$ & $\mathrm{LMS}_{5}$ & $\mathrm{LMS}_{6}$ \\
\hline \multirow{5}{*}{$S$} & $S^{l}$ & 0.049 & 0.025 & 0.123 & 0.045 & 0.059 & 0.035 \\
\hline & $S^{m}$ & 0.328 & 0.284 & 0.478 & 0.320 & 0.353 & 0.303 \\
\hline & $S^{u}$ & 1.105 & 1.022 & 1.404 & 1.101 & 1.166 & 1.066 \\
\hline & Crisp $(\widetilde{S})$ & 0.411 & 0.364 & 0.573 & 0.405 & 0.440 & 0.386 \\
\hline & Rank & 4 & 1 & 6 & 3 & 5 & 2 \\
\hline \multirow{5}{*}{$R$} & $R^{l}$ & 0.028 & 0.011 & 0.028 & 0.017 & 0.028 & 0.029 \\
\hline & $R^{m}$ & 0.072 & 0.048 & 0.083 & 0.064 & 0.081 & 0.082 \\
\hline & $R^{u}$ & 0.184 & 0.160 & 0.213 & 0.192 & 0.206 & 0.217 \\
\hline & Crisp $(\widetilde{R})$ & 0.083 & 0.061 & 0.096 & 0.077 & 0.093 & 0.095 \\
\hline & Rank & 3 & 1 & 6 & 2 & 4 & 5 \\
\hline \multirow{5}{*}{ Q } & $Q^{l}$ & -0.286 & -0.334 & -0.257 & -0.314 & -0.281 & -0.289 \\
\hline & $Q^{m}$ & 0.191 & 0.117 & 0.272 & 0.169 & 0.221 & 0.205 \\
\hline & $Q^{u}$ & 0.837 & 0.749 & 1.018 & 0.856 & 0.915 & 0.905 \\
\hline & Crisp $(\widetilde{Q})$ & 0.219 & 0.147 & 0.308 & 0.203 & 0.253 & 0.240 \\
\hline & Rank & 3 & 1 & 6 & 2 & 5 & 4 \\
\hline
\end{tabular}

Based on the presented results, it can be seen that there are no significant changes in the ranking of alternatives in any of the scenarios. Alternative $\mathrm{LMS}_{2}$ is the best and $\mathrm{LMS}_{3}$ the worst ranked in all scenarios. $\mathrm{LMS}_{4}$ ranks second in all scenarios except Sc.3 and Sc.7. Other alternatives changed the rank, but without significant deviations. Sensitivity analysis proved that the obtained solution in Sc.0 is sufficiently stable and can be adopted as the final.

\section{Discussion}

The possibility of applying the defined MCDM model was successfully demonstrated in the previous section. It has been shown that the FARE method is very suitable for obtaining criteria weights because it results in consistent values based on a small number of pair vise comparisons of criteria. This characteristic would be even more pronounced 
TABLE 7: Sensitivity analysis results.

\begin{tabular}{lccccccrrr}
\hline & Sc.0 & Sc.1 & Sc.2 & Sc.3 & Sc.4 & Sc.5 & Sc.6 & Sc.7 & Sc.8 \\
\hline$Q_{\mathrm{LMS}_{1}}$ & 0.219 & 0.285 & 0.290 & 0.244 & 0.302 & 0.235 & 0.249 & 0.199 & 0.246 \\
$\mathrm{LMS}_{2}$ & 0.147 & 0.138 & 0.155 & 0.169 & 0.209 & 0.144 & 0.166 & 0.148 & 0.157 \\
$\mathrm{Q}_{\mathrm{LMS}_{3}}$ & 0.308 & 0.400 & 0.361 & 0.362 & 0.422 & 0.290 & 0.336 & 0.308 & 0.319 \\
$Q_{\mathrm{LMS}_{4}}$ & 0.203 & 0.201 & 0.199 & 0.238 & 0.282 & 0.208 & 0.213 & 0.210 & 0.223 \\
$\mathrm{~L}_{\mathrm{LMS}}$ & 0.253 & 0.353 & 0.357 & 0.225 & 0.303 & 0.265 & 0.269 & 0.216 & 0.240 \\
$\mathrm{Q}_{\mathrm{LMS}}$ & 0.240 & 0.304 & 0.320 & 0.321 & 0.239 & 0.259 & 0.225 & 0.252 & 0.255 \\
\hline
\end{tabular}

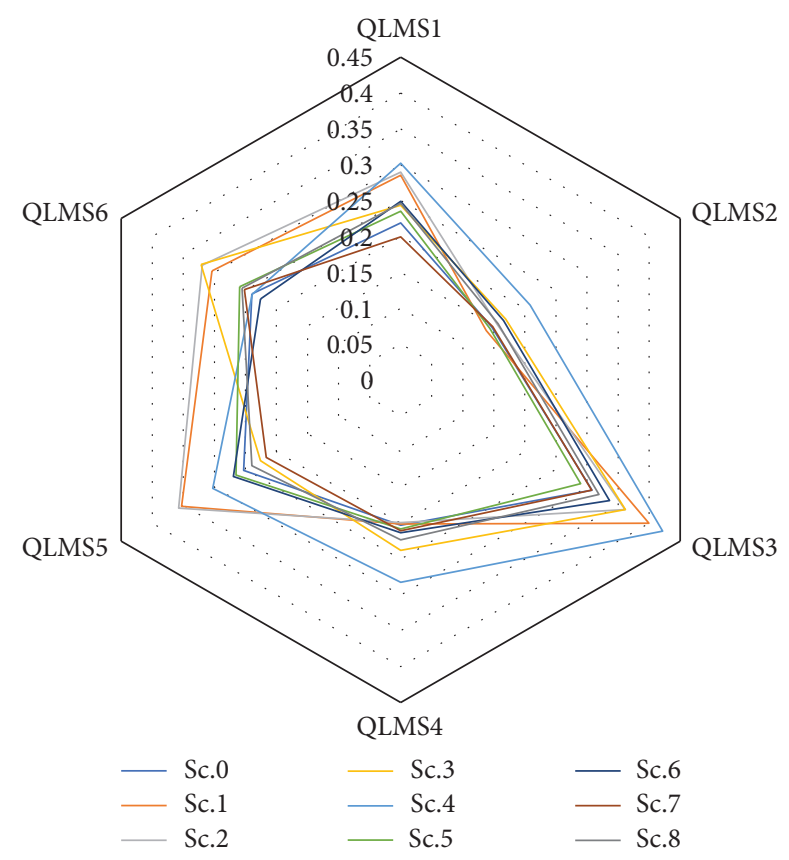

FIGURE 3: Sensitivity analysis. Eight scenarios, each differing according to the model parameters, were compared to the baseline scenario in order to examine the stability of the obtained solution.

in the case of considering a greater number of criteria. The Delphi method made it possible to easily consolidate the evaluation of criteria by the representatives of different stakeholders, which is the first step in finding a compromise solution. The VIKOR method has enabled the ranking of alternatives based on the values that determine their distance from the ideal solution much more precisely, compared to some other methods. The combination of these methods in the fuzzy environment, which enabled an adequate perception of ambiguity and inaccuracy in the evaluations of decision-makers, further contributed to the quality of the obtained results. The implications of the developed model are the possibility of its application for ranking any initiatives, technologies, concepts, or solutions of city logistics, as well as for solving other MCDM problems in the field of logistics and industrial engineering, as well as in other areas.

The defined MCDM model was applied in this paper for the evaluation of LMS for the central business district of Belgrade. $\mathrm{LMS}_{2}$ - the combination of the concept of microconsolidation of flows and autonomous vehicle technologies-is evaluated as being the best one. By locating microconsolidation centers in the immediate proximity of the flows generators, technical limitations of autonomous vehicles are overcome, and the efficiency of their application is improved. By transforming the system into a two-echelon system, the interdependence of flow performance is reduced in different levels-the transportation of goods to the microconsolidation centers and the delivery of goods to the generators. This means that after the delivery of goods to a microconsolidation center, the freight vehicle continues its task, while, at the same time, the last phase of the delivery is being adapted for the autonomous vehicles, thus improving the flexibility of the system. By selecting $\mathrm{LMS}_{2}$, significant positive effects on logistics sustainability in urban areas are expected-better activity efficiency, reduction of negative effects (airpollutant emissions, noise, vibrations, traffic congestions), the improvement in attractiveness of the central business district, and the promotion of the application of modern goods delivery technologies. The implementation of this solution is practically feasible, while the application of different autonomous vehicle classes (ground vehicles and drones) provides greater flexibility during the system's planning as well. Certainly, the implementation of the solution is preceded with solving all relevant problems on the strategical and tactical decision levels (the required number of microconsolidation centers, their locations and capacities, dimensioning the required number of 
autonomous vehicles in microconsolidation centers, etc.) and appropriate preparations for solving operational problems (vehicle routing and synchronization) during its exploitation. Besides, the application of such solutions opens a wide variety of questions regarding the definition of required regulatory frameworks for autonomous technologies, which have not received adequate treatment in the world so far.

The main theoretical implications of the paper are the development of a framework for the establishment of sustainable last mile solutions and efficient mathematical tool, in the form of a hybrid MCDM model, which can be used for solving the problems in the field of logistics, as well as any other. The main practical implications, on the other side, are the definition of the set of solutions that could serve as a good base for policy-making and plan development, in Belgrade or any other city, as well as the application of the developed model for selecting sustainable solutions for city logistics and last mile delivery by the decision-makers and practitioners.

\section{Conclusion}

The aim of this paper was to rank sustainable solutions for the realization of the last mile. The solutions defined in the paper are combinations of initiatives, technologies, and concepts of city logistics, and their application depends on the goals of different stakeholders. Accordingly, a set of criteria was defined for the evaluation of the solutions, and a novel MCDM model which combines Delphi, FARE, and VIKOR methods in the fuzzy environment was developed for solving the problem. The applicability of the defined model was demonstrated by ranking the sustainable LMSs for the central business district of Belgrade. A combination of microconsolidation centers and autonomous vehicles was obtained as the most favorable solution.

The main contributions of the paper are the definition of the innovative sustainable last mile solutions, the creation of a wide set of criteria for their evaluation, and the development of a novel hybrid MCDM model. In future research, the defined solutions could be upgraded, e.g., with some newly developed technologies of Industry 4.0. The potential effects of the application of defined solutions on the realization of logistics processes could also be examined in more detail, primarily in Belgrade, but also in some other cities. The defined MCDM model is universally applicable, and with certain adjustments, it could be used to solve various problems, so an important direction of future research is its application to solve problems in this or other areas. In addition, the model, or some of its parts, could serve as a basis for the development of some new MCDM models in the future.

\section{Data Availability}

All data underlying the findings of the study are included within the paper.

\section{Disclosure}

The research was performed as part of the employment of the authors at the University of Belgrade, Faculty of
Transport and Traffic Engineering, and Chalmers University of Technology.

\section{Conflicts of Interest}

The authors declare that there are no conflicts of interest regarding the publication of this paper.

\section{References}

[1] S. Tadic, S. Zecevic, and M. Krstic, "City logistics initiatives aimed at improving sustainability within existing context of urban area," Tehnika, vol. 69, no. 3, pp. 487-495, 2014.

[2] A. Paul, N. Shukla, S. K. Paul, and A. Trianni, "Sustainable supply chain management and multi-criteria decisionmaking methods: a systematic review," Sustainability, vol. 13, no. 3, p. 7104, 2021.

[3] M. Stojčić, E. K. Zavadskas, D. Pamučar, Ž. Stević, and A. Mardani, "Application of MCDM methods in sustainability engineering: a literature review," Symmetry, vol. 11, no. 3, p. 350, 2019.

[4] M. Mathew and S. Sahu, "Comparison of new multi-criteria decision making methods for material handling equipment selection," Management Science Letters, vol. 8, no. 3, pp. 139-150, 2018.

[5] P. Chowdhury and S. K. Paul, "Applications of MCDM methods in research on corporate sustainability," Management of Environmental Quality: An International Journal, vol. 31, no. 2, pp. 385-405, 2020.

[6] A. E. Wolnowska and W. Konicki, "Multi-criterial analysis of oversize cargo transport through the city, using the AHP method," Transportation Research Procedia, vol. 39, pp. 614-623, 2019.

[7] A. Calabrese, R. Costa, N. Levialdi, and T. Menichini, "Integrating sustainability into strategic decision-making: a fuzzy AHP method for the selection of relevant sustainability issues," Technological Forecasting and Social Change, vol. 139, pp. 155-168, 2019.

[8] L. Jurik, N. Hornakova, E. Šantava, D. Caganova, and J. Sablik, "Application of AHP method for project selection in the context of sustainable development," Wireless Networks, vol. 139, 2020.

[9] H. Han and S. Trimi, "A fuzzy TOPSIS method for performance evaluation of reverse logistics in social commerce platforms," Expert Systems with Applications, vol. 103, pp. 133-145, 2018.

[10] F. Samaie, H. Meyar-Naimi, S. Javadi, and H. Feshki-Farahani, "Comparison of sustainability models in development of electric vehicles in Tehran using fuzzy TOPSIS method," Sustainable Cities and Society, vol. 53, Article ID 101912, 2020.

[11] F. Lei, G. Wei, H. Gao, J. Wu, and C. Wei, “TOPSIS method for developing supplier selection with probabilistic linguistic information," International Journal of Fuzzy Systems, vol. 22, no. 3, pp. 749-759, 2020.

[12] L. Wang, H. Zhang, J. Wang, and L. Li, "Picture fuzzy normalized projection-based VIKOR method for the risk evaluation of construction project," Applied Soft Computing, vol. 64, pp. 216-226, 2020.

[13] F. Zhou, X. Wang, M. Goh, L. Zhou, and Y. He, "Supplier portfolio of key outsourcing parts selection using a two-stage decision making framework for Chinese domestic automaker," Computers and Industrial Engineering, vol. 128, pp. 559-575, 2019. 
[14] S. Narayanamoorthy, G. Selvaraj, R. Rakkiyappan, and Y. H. Joo, "Interval-valued intuitionistic hesitant fuzzy entropy based VIKOR method for industrial robots selection," Expert Systems with Applications, vol. 121, 2018.

[15] V.Simic, S. Karagoz, M. Deveci, and N. Aydin, "Picture fuzzy extension of the CODAS method for multi-criteria vehicle shredding facility location," Expert Systems with Applications, vol. 175, Article ID 114644, 2021.

[16] O. S. Cevik, K. Cengiz, and O. Basar, "A new hesitant fuzzy KEMIRA approach: an application to adoption of autonomous vehicles," Journal of Intelligent and Fuzzy Systems, pp. 1-12, 2021, In press.

[17] Z. Stević, Ž. Stjepanović, Z. Božičković, D. K. Das, and D. Stanujkić, "Assessment of conditions for implementing information technology in a warehouse system: a novel fuzzy PIPRECIA method," Symmetry, vol. 10, no. 11, p. 586, 2018.

[18] M. Stanković, Ž. Stević, D. K. Das, M. Subotić, and D. Pamučar, "A new fuzzy MARCOS method for road traffic risk analysis," Mathematics, vol. 8, no. 3, p. 457, 2020.

[19] F. Zhou, X. Wang, M. K. Lim, Y. He, and L. Li, "Sustainable recycling partner selection using fuzzy DEMATEL-AEWFVIKOR: a case study in small-and-medium enterprises (SMEs)," Journal of Cleaner Production, vol. 196, pp. 489504, 2018.

[20] P. Ma, N. Yao, and X. Yang, "Service quality evaluation of terminal express delivery based on an integrated SERVQUAL-AHP-TOPSIS approach," Mathematical Problems in Engineering, vol. 2021, Article ID 8883370, 2021.

[21] D. Xu, J. Ren, L. Dong, and Y. Yang, "Portfolio selection of renewable energy-powered desalination systems with sustainability perspective: a novel MADM-based framework under data uncertainties," Journal of Cleaner Production, vol. 275, no. 1-3, Article ID 124114, 2020.

[22] F. Zhou, M. K. Lim, Y. He, and S. Pratap, "What attracts vehicle consumers' buying," Industrial Management and Data Systems, vol. 120, no. 1, pp. 57-78, 2019.

[23] S. Tadić, M. Kilibarda, M. Kovač, and S. Zečević, "The assessment of intermodal transportation in countries of the Danube region," International Journal for Traffic and Transport Engineering, vol. 11, no. 3, pp. 375-391, 2021.

[24] E. K. Delice and G. F. Can, "A new approach for ergonomic risk assessment integrating KEMIRA, best-worst and MCDM methods," Soft Computing, vol. 24, pp. 15093-15110, 2020.

[25] R. Ginevičius, "A new determining method for the criteria weights in multicriteria evaluation," International Journal of Information Technology and Decision Making, vol. 10, no. 6, pp. 1067-1095, 2011.

[26] A. Krylovas, E. K. Zavadskas, N. Kosareva, and S. Dadelo, "New KEMIRA method for determining criteria priority and weights in solving MCDM problem," International Journal of Information Technology and Decision Making, vol. 13, no. 6, pp. 1119-1133, 2014.

[27] P. Chatterjee, S. Mondal, S. Boral, A. Banerjee, and S. Chakraborty, "A novel hybrid method for non-traditional machining process selection using factor relationship and multi-attributive border approximation method," $\mathrm{FU} \mathrm{Me-}$ chanical Engineering, vol. 15, no. 3, pp. 439-456, 2017.

[28] H. Kazan, S. Özçelik, and E. H. Hobikoğlu, "Election of deputy candidates for nomination with AHP-promethee methods," Procedia-Social and Behavioral Sciences, vol. 195, pp. 603-613, 2015.

[29] J. Roy, D. Pamučar, and S. Kar, "Evaluation and selection of third-party logistics provider under sustainability perspectives: an interval valued fuzzy-rough approach," Annals of Operations Research, vol. 293, pp. 669-714, 2020.

[30] M. Yazdani, "New approach to select materials using MADM tools," International Journal of Business and Systems Research, vol. 12, no. 1, pp. 25-42, 2018.

[31] J. Stankevičienè, L. Kraujalienè, and A. Vaiciukevičiūtè, "Assessment of technology transfer office performance for value creation in higher education institutions," Journal of Business Economics and Management, vol. 18, no. 6, pp. 1063-1081, 2017.

[32] P. Pitchipoo, D. S. Vincent, N. Rajini, and S. Rajakarunakaran, "COPRAS decision model to optimize blind spot in heavy vehicles: a comparative perspective," Procedia Engineering, vol. 97, pp. 1049-1059, 2014.

[33] N. C. Dalkey and O. Helmer, "An experimental application of the Delphi method to the use of experts," Management Science, vol. 9, no. 3, pp. 458-467, 1963.

[34] A. L. Delbecq, A. H. Van De Ven, and D. H. Gustafson, Group Techniques for Program Planning: A Guide to Nominal Group and Delphi Processes, Scott Foresman, Glenview, IL, USA, 1975.

[35] Y.-C. Shen, G. T. R. Lin, and G.-H. Tzeng, "Combined DEMATEL techniques with novel MCDM for the organic light emitting diode technology selection," Expert Systems with Applications, vol. 38, pp. 1468-1481, 2011.

[36] A. Ishikawa, M. Amagasa, T. Shiga, G. Tomizawa, R. Tatsuta, and H. Mieno, "The max-min Delphi method and fuzzy Delphi method via fuzzy integration," Fuzzy Sets and Systems, vol. 55, no. 3, pp. 241-253, 1993.

[37] T. J. Murry, L. L. Pipino, and J. P. Gigch, "A pilot study of fuzzy set modification of Delphi," Human Systems Management, vol. 5, no. 1, pp. 76-80, 1985.

[38] D. J. Pojadas and M. L. S. Abundo, "A web-based Delphi multi-criteria group decision-making framework for renewable energy project development processes," International Journal of Management and Decision Making, vol. 19, no. 4, pp. 426-449, 2020.

[39] S. Tadić, M. Krstić, V. Roso, and N. Brnjac, "Dry port terminal location selection by applying the hybrid grey MCDM model," Sustainability, vol. 12, no. 17, p. 6983, 2020.

[40] S. Zečević, S. Tadić, and M. Krstić, "Intermodal transport terminal location selection using a novel hybrid MCDM model," International Journal of Uncertainty, Fuzziness and Knowledge-Based Systems, vol. 25, pp. 853-876, 2017.

[41] S. Zha, Y. Guo, S. Huang, and S. Wang, "A hybrid MCDM method using combination weight for the selection of facility layout in the manufacturing system: a case study," Mathematical Problems in Engineering, vol. 2020, Article ID 1320173, 16 pages, 2020.

[42] S. Tadić, M. Krstić, and S. Zečević, "Defining the typical structures of the intermodal terminals," in Quantitative Methods in Logistics, M. Vidović, M. Kilibarda, S. Zečević, and G. Radivojević, Eds., pp. 67-86, Faculty of Transport and Traffic Engineering, University of Belgrade, Belgrade, Serbia, 2020b.

[43] H. Zhao, S. Guo, and H. Zhao, "Comprehensive assessment for battery energy storage systems based on fuzzy-MCDM considering risk preferences," Energy, vol. 168, pp. 450-461, 2019.

[44] S. Tadić, M. Krstić, V. Roso, and N. Brnjac, "Planning an intermodal terminal for the sustainable transport networks," Sustainability, vol. 11, no. 15, pp. 1-20, 2019. 
[45] S. Opricovic, Multi-Criteria Optimization of Civil Engineering Systems, Faculty of Civil Engineering, Belgrade, Serbia, 1998.

[46] W. H. Tsai, W. C. Chou, and J. D. Leu, "An effectiveness evaluation model for the web-based marketing of the airline industry," Expert Systems with Applications, vol. 38, no. 12, pp. 15499-15516, 2011.

[47] N. Caterino, I. Iervolino, G. Manfredi, and E. Cosenza, "A comparative analysis of decision-making methods for the seismic retrofit of RC buildings," in Proceedings of the 14th World Conference on Earthquake Engineering, Beijing, China, October 2008.

[48] S. Opricovic and G. H. Tzeng, "Compromise solution by MCDM methods: a comparative analysis of VIKOR and TOPSIS," European Journal of Operational Research, vol. 156, no. 2, pp. 445-455, 2004.

[49] S. Opricovic and G. H. Tzeng, "Extended VIKOR method in comparison with outranking methods," European Journal of Operational Research, vol. 178, pp. 514-529, 2007.

[50] S. Opricovic, "A fuzzy compromise solution for multicriteria problems," International Journal of Uncertainty, Fuzziness and Knowledge-Based Systems, vol. 15, no. 3, pp. 363-380, 2007.

[51] H. Li, W. Wang, L. Fan, Q. Li, and X. Chen, "A novel hybrid MCDM model for machine tool selection using fuzzy DEMATEL, entropy weighting and later defuzzification VIKOR," Applied Soft Computing, vol. 91, pp. 1-14, 2020.

[52] S. Tadić, S. Zečević, and M. Krstić, "Sustainability of the city logistics initiatives," in Proceedings of The 3rd Logistics International Conference, LOGIC 2017, pp. 44-49, Faculty of Transport and Traffic Engineering, University of Belgrade, Belgrade, Serbia, May 2017.

[53] G. Büyüközkan, O. Feyzioğlu, and F. Gocer, "Evaluation of hospital web services using intuitionistic fuzzy AHP and intuitionistic fuzzy VIKOR," in Proceedings of the 2016 IEEE International Conference on Industrial Engineering and Engineering Management (IEEM), pp. 607-611, Bali, Indonesia, December 2016.

[54] S. Zečević, S. Tadić, and M. Krstić, "Multi-criteria evaluation of the intermodal terminal technologies," in Proceedings of the 3rd Logistics International Conference, LOGIC 2017, pp. 105-110, Faculty of Transport and Traffic Engineering, University of Belgrade, Belgrade, Serbia, May 2017.

[55] C. K. Lin, Y. S. Chen, and H. M. Chuang, "Improving project risk management by a hybrid MCDM model combining DEMATEL with DANP and VIKOR methods-an example of cloud CRM," in Frontier Computing, J. Hung, N. Yen, and K. C. Li, Eds., Springer, Singapore, pp. 1033-1040, 2016.

[56] S. Tadić, S. Zečević, and M. Krstić, "A novel hybrid MCDM model based on fuzzy DEMATEL, fuzzy ANP and fuzzy VIKOR for city logistics concept selection," Expert Systems with Applications, vol. 41, pp. 8112-8128, 2014.

[57] M. Janjević, P. Lebeau, A. B. Ndiaye, C. Macharis, J. Van Mierlo, and A. Nsamzinshuti, "Strategic scenarios for sustainable urban distribution in the Brussels-capital region using urban consolidation centres," Transportation Research Procedia, vol. 12, pp. 598-612, 2016.

[58] S. Tadić, S. Zečević, and M. Krstić, "City logistics-status and trends," International Journal for Traffic and Transport Engineering, vol. 5, no. 3, pp. 319-343, 2015.

[59] A. Caliskan, M. Kalkan, and Y. Ozturkoglu, "City logistics: problems and recovery proposals," International Journal of Logistics Systems and Management, vol. 26, no. 2, pp. 145$162,2017$.
[60] J. Rzesny-Cieplinska and A. Szmelter-Jarosz, "Environmental sustainability in city logistics measures," Energies, vol. 13, no. 6, p. 1303, 2020.

[61] L. Švadlenka, V. Simić, M. Dobrodolac, D. Lazarević, and G. Todorović, "Picture fuzzy decision-making approach for sustainable last-mile delivery," IEEE Access, vol. 8, pp. 209393-209414, 2020.

[62] G. Büyüközkan and D. Uztürk, "A hybrid methodology for last mile delivery strategy and solution selection at smart cities," in Transactions on Engineering Technologies, World Congress on Engineering 2019, S. I. Ao, H.-K. Kim, and L. Gelman, Eds., pp. 217-232, Springer, Heidelberg, Germany, 2019.

[63] G. Büyüközkan and F. Göçer, "Prioritizing the strategies to enhance smart city logistics by intuitionistic fuzzy CODAS," in Proceedings of the 11th Conference of the European Society for Fuzzy Logic and Technology-EUSFLAT, Prague, Czech Republic, September 2019.

[64] S. Tadić, S. Zečević, and M. Krstić, “Assessment of the political city logistics initiatives sustainability," Transportation Research Procedia, vol. 30, pp. 285-294, 2018.

[65] A. Awasthi and S. S. Chauhan, "A hybrid approach integrating affinity diagram, AHP and fuzzy TOPSIS for sustainable city logistics planning," Applied Mathematical Modelling, vol. 36, pp. 573-584, 2012.

[66] S. Tadić, M. Kovač, and O. Čokorilo, "The application of drones in city logistics concepts," Promet-Traffic and Transportation, vol. 33, no. 3, pp. 451-462, 2021.

[67] S. Tadić, S. Zečević, and M. Krstić, "Ranking of logistics system scenarios for central business district," Promet-Traffic and Transportation, vol. 26, no. 2, 159-167, 2014.

[68] P. Lebeau, C. Macharis, J. Van Mierlo, and M. Janjević, "Improving policy support in city logistics: the contributions of a multi-actor multi-criteria analysis," Case Studies on Transport Policy, vol. 6, no. 4, pp. 554-563, 2018.

[69] S. Raicu, D. Costescu, and S. Burciu, "Distribution system with flow consolidation at the boundary of urban congested areas," Sustainability, vol. 12, no. 3, p. 990, 2020.

[70] W. Van Heeswijk, R. Larsen, and A. Larsen, "An urban consolidation center in the city of Copenhagen: a simulation study," International Journal of Sustainable Transportation, vol. 13, no. 9, pp. 1-17, 2019.

[71] M. Leyerer, M.-O. Sonneberg, M. Heumann, and M. H. Breither, "Shortening the last mile in urban areas: optimizing a smart logistics concept for e-grocery operations," Smart Cities, vol. 3, no. 3, pp. 585-603, 2020.

[72] S. Tadić and S. Zečević, "Cooperation and consolidation of flows in city logistics," Tehnika, vol. 62, no. 4, pp. 687-694, 2015.

[73] S. Zečević and S. Tadić, "Cooperation models for city logistics," Transport and Logistics, vol. 9, pp. 123-141, 2005.

[74] M. Björklund and H. Johansson, "Urban consolidation centre-a literature review, categorisation, and a future research agenda," International Journal of Physical Distribution and Logistics Management, vol. 48, no. 8, pp. 745-764, 2017.

[75] P. Lebeau, S. Verlinde, C. Macharis, and J. Van Mierlo, "How can authorities support urban consolidation centres? a review of the accompanying measures," Journal of Urbanism, vol. 10, no. 4, pp. 468-486, 2017.

[76] J. Allen, M. Browne, A. Woodburn, and J. Leonardi, "A review of urban consolidation centres in the supply chain based on a case study approach," Supply Chain Forum, vol. 15, no. 4, pp. 100-111, 2015. 
[77] L. Faugere, C. C. White, and B. Montreuil, "Mobile access hub deployment for urban parcel logistics," Sustainability, vol. 12, no. 17, p. 7213, 2020.

[78] M. Janjević and A. B. Ndiaye, "Development and application of a transferability framework for micro-consolidation schemes in urban freight transport," Procedia-Social and Behavioral Sciences, vol. 125, pp. 285-296, 2014 a.

[79] M. Jeremić and M. Andrejić, "Crowd logistics-a new concept in realization of logistics services," in Proceedings of the 4th Logistics International Conference, LOGIC 2019, pp. 170-179, Belgrade, Serbia, May 2019.

[80] E. Estelles-Arolas and F. G. L. Guevara, "Towards an integrated crowdsourcing definition," Journal of Information Science, vol. 38, no. 2, pp. 189-200, 2012.

[81] Y. Wang, D. Zhang, Q. Liu, F. Shen, and L. H. Lee, “Towards enhancing the last-mile delivery: an effective crowd-tasking model with scalable solutions," Transportation Research Part E, vol. 93, pp. 279-293, 2016.

[82] K. Huang and M. N. Ardiansyah, "A decision model for lastmile delivery planning with crowdsourcing integration," Computers and Industrial Engineering, vol. 135, pp. 898-912, 2019.

[83] W. Qi, L. Li, S. Liu, and M. Shen, "Shared mobility for lastmile delivery: design, operational prescriptions, and environmental impact," Manufacturing and Service Operations Management, vol. 20, no. 4, pp. 737-751, 2018.

[84] A. Giret, C. Carrascosa, V. Julian, M. Rebollo, and V. Botti, "A crowdsourcing approach for sustainable last mile delivery," Sustainability, vol. 10, no. 12, p. 4563, 2018.

[85] V. E. Castillo, J. Bell, W. Rose, and A. Rodrigues, "Crowdsourcing last mile delivery: strategic implications and future research directions," Journal of Business Logistics, vol. 39, no. 2, pp. 7-25, 2018.

[86] A. Devari, A. G. Nikolaev, and Q. He, "Crowdsourcing the last mile delivery of online orders by exploiting the social networks of retail store customers," Transportation Research Part E, vol. 105, pp. 105-122, 2017.

[87] J. Maes, C. Sys, and T. Vanelslander, "City logistics by water: good practices and scope for expansion," in Transport of Water versus Transport over Water. Operations Research/ Computer Science Interfaces Series, C. Ocampo-Martinez and R. R. Negenborn, Eds., vol. 58, pp. 413-437, Springer, Heidelberg, Germany, 2015.

[88] M. Janjević and A. B. Ndiaye, "Inland waterways transport for city logistics: a review of experiences and the role of local public authorities," WIT Transactions on the Built Environment, vol. 138, pp. 279-290, 2014.

[89] D. Diziain, E. Taniguchi, and L. Dablanc, "Urban logistics by rail and waterways in France and Japan," Procedia-Social and Behavioral Sciences, vol. 125, pp. 159-170, 2014.

[90] K. Wojewodzka-Krol and R. Rolbiecki, "The role of inland waterway transport in city logistics," Transport Economics and Logistics, vol. 84, pp. 103-114, 2019.

[91] M. Strale, "The cargo tram: current status and perspectives, the example of Brussels," in Sustainable Logistics, C. Macharis, S. Melo, J. Woxenius, and T. Van Lier, Eds., Emerald Group Publishing Limited, Bingley, UK, 2014.

[92] M. Zych, "Identification of potential implementation of the Cargo tram in Warsaw: a first overview," Procedia-Social and Behavioral Sciences, vol. 151, pp. 360-369, 2014.

[93] N. Arvidsson and M. Browne, "A review of the success and failure of tram systems to carry urban freight: the implications for a low emission intermodal solution using electric vehicles on trams," European Transport $\backslash$ Transporti Europei, vol. 54, no. 5, pp. 1-18, 2013.

[94] E. Fatnassi, J. Chaouachi, and W. Klibi, "Planning and operating a shared goods and passengers on-demand rapid transit system for sustainable city-logistics," Transportation Research Part B, vol. 81, pp. 440-460, 2015.

[95] C. Pimentel and F. Alvelos, "Integrated urban freight logistics combining passenger and freight flows -mathematical model proposal," Transportation Research Procedia, vol. 30, pp. 80-89, 2018.

[96] R. Van Duin, B. Wiegmans, L. Tavasszy, B. Hendriks, and Y. He, "Evaluating new participative city logistics concepts: the case of cargo hitching," Transportation Research Procedia, vol. 39, pp. 565-575, 2019.

[97] Y. Vakulenko, D. Hellström, and K. Hjort, "What's the parcel locker? exploring customer value in e-commerce last mile delivery," Journal of Business Research, vol. 88, pp. 421-427, 2018.

[98] R. Ducret, "Parcel deliveries and urban logistics: changes and challenges in the courier express and parcel sector in Europe-the French case," Research in Transportation Business and Management, vol. 11, pp. 15-22, 2014.

[99] J. M. Gonzalez-Varona, F. Villafañez, F. Acebes, A. Redondo, and D. Poza, "Reusing newspaper kiosks for last-mile delivery in urban areas," Sustainability, vol. 12, no. 22, p. 9770, 2020.

[100] R. Van Duin, B. Wiegmans, B. Van Arem, and Y. Van Amstel, "From home delivery to parcel lockers: a case study in Amsterdam," Transportation Research Procedia, vol. 46, pp. 37-44, 2020.

[101] H. Quak, N. Nesterova, and T. Van Rooijen, "Possibilities and barriers for using electric-powered vehicles in city logistics practice," Transportation Research Procedia, vol. 12, pp. 157-169, 2016.

[102] J. Jones, A. Genovese, and A. Tob-Ogu, "Hydrogen vehicles in urban logistics: a total cost of ownership analysis and some policy implications," Renewable and Sustainable Energy Reviews, vol. 119, Article ID 109595, 2020.

[103] H. S. Das, W. C. Tan, and A. H. M. Yatim, "Fuel cell hybrid electric vehicles: a review on power conditioning units and topologies," Renewable and Sustainable Energy Reviews, vol. 76, pp. 268-291, 2017.

[104] C. Rudolph and J. Gruber, "Cargo cycles in commercial transport: potentials, constraints, and recommendations," Research in Transportation Business and Management, vol. 24, pp. 26-36, 2017.

[105] S. Melo and P. Baptista, "Evaluating the impacts of using cargo cycles on urban logistics: integrating traffic, environmental and operational boundaries," European Transport Research Review, vol. 9, no. 2, pp. 9-30, 2017.

[106] A. Conway, J. Cheng, C. Kamga, and D. Wan, "Cargo cycles for local delivery in New York city: performance and impacts," Research in Transportation Business and Management, vol. 24, pp. 90-100, 2017.

[107] G. Schliwa, R. Armitage, S. Aziz, J. Evans, and J. Rhoades, "Sustainable city logistics-Making cargo cycles viable for urban freight transport," Research in Transportation Business and Management, vol. 15, pp. 50-57, 2015.

[108] D. L. J. U. Enthoven, B. Jargalsaikhan, K. J. Roodbergen, M. A. J. Uit Het Broek, and A. H. Schrotenboer, "The twoechelon vehicle routing problem with covering options: city logistics with cargo bikes and parcel lockers," Computers and Operations Research, vol. 118, Article ID 104919, 2020. 
[109] G. Perboli, M. Rosano, M. Saint-Guillain, and P. Rizzo, “A simulation-optimization framework for city logistics: an application on multimodal last-mile delivery," IET Intelligent Transport Systems, vol. 12, no. 4, pp. 262-269, 2018.

[110] R. Nocerino, A. Colorni, F. Lia, and A. Lue, "E-bikes and E-scooters for smart logistics: environmental and economic sustainability in pro-E-bike Italian pilots," Transportation Research Procedia, vol. 14, pp. 2362-2371, 2016.

[111] S. Kumar and R. S. Bharj, "Solar hybrid e-cargo rickshaw for urban transportation demand in India," Transportation Research Procedia, vol. 48, pp. 1998-2005, 2020.

[112] M. A. Figliozzi, "Carbon emissions reductions in last mile and grocery deliveries utilizing air and ground autonomous vehicles," Transportation Research Part D, vol. 85, Article ID $102443,2020$.

[113] T. Hoffmann and G. Prause, "On the regulatory framework for last-mile delivery robots," Machines, vol. 6, no. 3, p. 33, 2018.

[114] L. Baum, T. Assmann, and H. Strubelt, "State of the art-automated micro-vehicles for urban logistics," IFAC PapersOnLine, vol. 52, no. 13, pp. 1455-2462, 2019.

[115] D. Jennings and M. Figliozzi, "Study of sidewalk autonomous delivery robots and their potential impacts on freight efficiency and travel," Transportation Research Record, vol. 2673, no. 6, pp. 317-326, 2019.

[116] E. E. Yurek and H. C. Ozmutlu, "A decomposition-based iterative optimization algorithm for traveling salesman problem with drone," Transportation Research Part C, vol. 91, pp. 249-262, 2018.

[117] C. C. Murray and A. G. Chu, "The flying sidekick traveling salesman problem: optimization of drone-assisted parcel delivery," Transportation Research Part C, vol. 54, pp. 86109, 2015.

[118] D. Popović, M. Kovač, and N. Bjelić, "A MIQP model for solving the vehicle routing problem with drones," in Proceedings of the 4th Logistics International Conference, LOGIC 2019, pp. 52-62, Belgrade, Serbia, May 2019.

[119] A. Karak and K. Abdelghany, "The hybrid vehicle-drone routing problem for pick-up and delivery services," Transportation Research Part C, vol. 102, pp. 427-449, 2019.

[120] S. Mourelo Ferrandez, T. Harbison, T. Weber, R. Sturges, and R. Rich, "Optimization of a truck-drone in tandem delivery network using k-means and genetic algorithm," Journal of Industrial Engineering and Management, vol. 9, no. 2, pp. 374-388, 2016.

[121] I. Dayarian, M. Savelsbergh, and J.-P. Clarke, "Same day delivery with drone resupply," Transportation Science, vol. 54, no. 1, pp. 1-21, 2020.

[122] J. Kim, H. Moon, and H. Jung, "Drone-based parcel delivery using rooftops of city buildings: model and solution," Applied Sciences, vol. 10, no. 12, pp. 4362-4381, 2020.

[123] J. Kim and I. Moon, "Traveling salesman problem with a drone station," IEEE Transactions on Systems, Man, and Cybernetics: Systems, vol. 99, pp. 1-11, 2018.

[124] Z. Chen, J. Dong, and R. Ren, "Urban underground logistics system in China: opportunities or challenge?," Underground Space, vol. 2, no. 3, pp. 195-208, 2017.

[125] D. Hai, J. Hu, Z. Duan, and C. Chen, "Effects of underground logistics system on urban freight traffic: a case study in Shangai, China," Journal of Cleaner Production, vol. 260, Article ID 121019, 2020.

[126] A. Van Binsbergen and P. Bovy, "Underground urban goods distribution networks," Innovation: The European Journal of Social Science Research, vol. 13, no. 1, pp. 111-128, 2000.
[127] M. Turkowski and M. Szudarek, "Pipeline system for transporting consumer goods, parcels and mail in capsules," Tunnelling and Underground Space Technology, vol. 93, Article ID 103057, 2019.

[128] J. G. S. N. Visser, "The development of underground freight transport: an overview," Tunnelling and Underground Space Technology, vol. 80, pp. 123-127, 2018.

[129] A. Szmelter-Jarosz and J. Rzesny-Cieplinska, "Priorities of urban transport system stakeholders according to crowd logistics solutions in city areas: a sustainability perspective," Sustainability, vol. 12, no. 317, 2020.

[130] T. H. Hsu and T. H. Yang, "Application of fuzzy analytic hierarchy process in the selection of advertising media," Journal of Management Systems, vol. 7, pp. 19-39, 2000.

[131] S. Opricovic, "Fuzzy VIKOR with an application to water resources planning," Expert Systems with Applications, vol. 38, pp. 12983-12990, 2011.

[132] A. C. Kutlu and M. Ekmekcioglu, "Fuzzy failure modes and effects analysis by using fuzzy TOPSIS-based fuzzy AHP," Expert Systems with Applications, vol. 39, pp. 61-67, 2012.

[133] S. Zečević and S. Tadić, "City Logistics" (In Serbian), University of Belgrade, Faculty of Transport and Traffic Engineering, Belgrade, Serbia, 2006. 